\title{
Recent advances in nanotheranostics for triple negative breast cancer treatment
}

\author{
Vikram Thakur $^{1}$ and Rajaletchumy Veloo Kutty ${ }^{2,3^{*}}$ (D)
}

\begin{abstract}
Triple-negative breast cancer (TNBC) is the most complex and aggressive type of breast cancer encountered world widely in women. Absence of hormonal receptors on breast cancer cells necessitates the chemotherapy as the only treatment regime. High propensity to metastasize and relapse in addition to poor prognosis and survival motivated the oncologist, nano-medical scientist to develop novel and efficient nanotherapies to solve such a big TNBC challenge. Recently, the focus for enhanced availability, targeted cellular uptake with minimal toxicity is achieved by nano-carriers. These smart nano-carriers carrying all the necessary arsenals (drugs, tracking probe, and ligand) designed in such a way that specifically targets the TNBC cells at site. Articulating the targeted delivery system with multifunctional molecules for high specificity, tracking, diagnosis, and treatment emerged as theranostic approach. In this review, in addition to classical treatment modalities, recent advances in nanotheranostics for early and effective diagnostic and treatment is discussed. This review highlighted the recently FDA approved immunotherapy and all the ongoing clinical trials for TNBC, in addition to nanoparticle assisted immunotherapy. Futuristic but realistic advancements in artificial intelligence (Al) and machine learning not only improve early diagnosis but also assist clinicians for their workup in TNBC. The novel concept of Nanoparticles induced endothelial leakiness (NanoEL) as a way of tumor invasion is also discussed in addition to classical EPR effect. This review intends to provide basic insight and understanding of the novel nano-therapeutic modalities in TNBC diagnosis and treatment and to sensitize the readers for continue designing the novel nanomedicine. This is the first time that designing nanoparticles with stoichiometric definable number of antibodies per nanoparticle now represents the next level of precision by design in nanomedicine.
\end{abstract}

Keywords: Breast Cancer, Nanomedicine, Theranostics, Immunotherapy, NanoEL, Nanotechnology

\section{Background}

Breast cancer $(\mathrm{BC})$ is the most common malignancy with 266,120 new cases and leading cause of cancer-related mortality (40,920 BC deaths) among women worldwide [1, 2]. Microarray-based expression profiling revealed the existence of five intrinsic subgroups of $\mathrm{BC}$ [3]. Triple-negative breast cancer (TNBC) owes $15-20 \%$ of all the invasive subtypes of breast cancer [4] and characterized by absence of expression of estrogen receptors (ER), progesterone receptors (PR) and human epidermal growth factor receptor 2 (HER-2) on tumors cell membrane. Based on the biological

\footnotetext{
* Correspondence: vrajaletchumy@ump.edu.my

${ }^{2}$ Faculty of Chemical and Process Engineering Technology, College of Engineering Technology,University Malaysia Pahang, Tun Razak Highway, 26300 Kuantan, Pahang, Malaysia

${ }^{3}$ Center of Excellence for Advanced Research in Fluid Flow, University

Malaysia Pahang, 26300, Kuantan, Pahang, Malaysia

Full list of author information is available at the end of the article
}

network-driven approach, Bonsang-Kitzis et al identified six TNBC subgroups whereas Burstein at al identified four stable TNBC subgroups based on mRNA expression and DNA genomic profiling $[5,6]$. Lack of hormone receptors (ER/PR/HER-2) in TNBC eliminates the benefits of endocrine therapy and treatment, therefore mainly relies on chemotherapy [7]. Even systemic chemotherapy with clinically approved drugs reflects poor response, high toxicity and develops multidrug resistance. In addition, molecular heterogeneity, high risk to metastasize preferentially to the viscera, high relapse rate and $B R C A$ mutations $\left(B R C A^{*}\right)$ contribute to poor prognosis and management [8-10].

For early therapeutic intervention, precise diagnosis is crucial. So far palpation, mammography, ultrasonography, ultrasound, magnetic resonance imaging (MRI) and immuno-histochemistry (IHC) are best TNBC diagnostics in the clinical setup. However, inaccurate diagnosis using

(C) The Author(s). 2019 Open Access This article is distributed under the terms of the Creative Commons Attribution 4.0 International License (http://creativecommons.org/licenses/by/4.0/), which permits unrestricted use, distribution, and 
non-specific contrast agents, false positive findings and examiner experience are the limiting and decisive factors to validate TNBC diagnosis. In addition, therapeutic interventions are limited to surgery, radiotherapy in addition to cytotoxic chemotherapy with taxanes and anthracyclines [11]. These limitations obviate the need to improve the currently available diagnostic and therapeutic in addition to explore the novel methods and approaches.

Last two decades of nano-technological advancements exploring biomedical science for cancer therapy with contrast agents and drug delivery carriers, now heading towards more precise and targeted co-delivery of both diagnostic and therapeutic agents. The availability of wide variety of nano-carriers were made from polymers, lipids, nucleic acid, proteins, carbon and metals including micelles, dendrimers, liposomes, nanoparticles/tubes, and DNA tetrahedral /pyramids [12-16]. These smart nanoparticles encapsulating anti-tumor drugs (arsenal), and surface coated with specific ligand (key) that eventually bind with the receptor (lock) expressing on the $\mathrm{BC}$ site (target) and destroy the cells in addition to molecular imaging (tracer agents) allowing us to simultaneously diagnose and treat the cancer i.e. Thenanostic approach for improving current cancer diagnosis and treatment regime. In recent years, theranostic approach has become more evident to develop efficient drug delivery system which will be able to cross the biological barriers for the delivery of right amount of drug at designated location and at/for appropriate time finally reduces side effects and improves therapeutic efficiency [17]. Although there is no FDA approved theranostic for TNBC, current approaches in conjugation with novel therapeutic modules are still indispensable need in clinical setup. As the therapeutic options for TNBC are limited, implementation of cancer immunotherapy has been successful in treating many malignancies. Recently, FDA granted approval to atezolizumab as first immunotherapy for TNBC treatment. So, it is worth exploring immunotherapies and performing clinical studies for treating TNBC patients with immunotherapy $[18,19]$.

\section{Triple-negative breast cancer: Current conventional diagnosis and therapeutics}

In clinical setup, radiological, clinical, and pathological examinations are the main diagnostic approaches for BC diagnosis. Most widely applied radiological examination is mammography (using $\mathrm{x}$-ray), but lack of abnormal features in TNBC tumors, resulting to an inaccurate diagnosis [20]. To overcome the mammography limitations, ultrasonography representing higher sensitivity $(>90 \%)$ should be considered [21], but limited accuracy for benign tumors, restricts the use for TNBC detection. MRI is the sensitive with high positive predictive values in TNBC diagnosis, resulting in false positive findings which eventually lead to avoidable painful biopsies [22]. Accuracy of TNBC detection by above radiological examinations requires expertise and experience with clinicians to ever evolving radio-graphical technologies and new cancer/tumor modalities like benign or early stage cancer. So, the role of immunohistochemistry (IHC) and onco-pathologist/clinicians is crucial in the clinical identification of TNBC. The immunohistochemical identification of TNBC relies on the hallmark property of absence/lack of hormonal receptors (ER, PR) and HER-2 in patient's biopsy tissues [23] and evaluated as best TNBC diagnosis.

After the proper TNBC diagnosis and considering other factors like metastatic nature, drug sensitivity/resistance, recurrence and poor prognosis, therapeutic intervention is done. Breast conservation treatment (BCT) is the first choice and attempt to avoid mastectomy in TNBC. However, the high incidence of tumor recurrence even after undergoing radiation treatment (RT), insist the patient for mastectomy in addition to radiotherapy [24]. Hormonal therapy which is successful in other subtype of breast cancer is not applicable to TNBC due to lack of HER2 and hormonal ER and PR receptors, thereby necessitates the chemotherapy, which is currently the mainstay of systemic treatment [25]. Chemotherapeutic drugs like anthracyclins and taxanes are commonly used for breast cancer treatment showing promising response in TNBC [26], but inherited cytotoxic effects and current non-targeted strategy of drug administration need to be resolved with novel technologies. Repeated chemo cycles with high doses of cytotoxic drugs destroy cancer cells in addition to the healthy cells in the vicinity. To avoid the non-specific targeting and chemo side-effect, nanotechnology based drug delivery systems are a promising tool. Recent advancements in nanotechnology and articulation of diagnostics with therapeutics in theranostic approach as a co-delivery system, not only the target the cancer selectively but also eliminate the cytotoxicity of drugs to other organ.

\section{Nanotechnology-advancements for TNBC: Targeted Theranostics}

In nano-science, developing a promising nanoparticle entails numerous physiochemical, biological and functional properties for biomedicine application. The most important is the size; the desired size of nanoparticles (1-200 nm) and conformation decide the trajectory dynamics of the particles which is decisive for nanomedicine formulation. In addition, surface charge and encapsulation capacity of the nanoparticle are the key factors for the precise targeted drug delivery using specific conjugated ligand against the target receptor on cancer cell. Other properties like high drug loading efficiency, long half-life in circulation with minimum 
systemic toxicity, selective localization, high adhesion at the tumor environment, enhanced internalization into the tumor via endocytosis, sustained and controlled release of imaging agents and cytotoxic drug over right duration and time in addition to safe bio-elimination from the body are significant for nanoparticles to be as theranostics in cancer diagnosis and treatment [27]. Majority of the above nano-delivery systems rely on the enhanced permeation and retention (EPR) effect for targeted drug delivery. Technical feasibility (high recovery with controlled drug loading and releasing) and financial stability for the large-scale production, also determine the success and research on cancer nanomedicine. However, application of nano-medicine is limited in TNBC due to lack of known highly expressed tumor target and ligands.

\section{Liposomal nanoparticles: A versatile spherical nanocarrier}

Liposomes are spherical vesicles $(400 \mathrm{~nm})$ molecule with central aqueous core surrounded by lipid bilayers (Table 1). The feasibility to encapsulate drug either in lipid membrane or inside the aqueous core, mark the liposomes the most versatile nanocarriers with better drug distribution. Generally, liposomal nanoparticles are designed by the different methods i.e. extrusion (process of producing nanoparticles of fixed cross-sectional area), solvent injection (method of lipid precipitation from a dissolved lipid in solution) and reverse phase evaporation. Dai et al,[28] targeted the overexpressing integrin- $\alpha 3$ in TNBC models with cyclic octapeptide LXY (Cys-Asp-Gly-Phe (3,5-DiF)-Gly-Hyp-Asn-Cys) attached liposomes carrying dual drug i.e. doxorubicin and rapamycin (Table 1). This dual drug targeted approach resulted in improved efficacy as compared to free drug. Similarly, enhanced antitumor activity in TNBC xenograft mice model has shown with doxorubicin and sorafenib loaded liposomes [29]. However, currently marketed doxorubicin liposomal formulations are associated with cardiotoxicity, a novel micelle-encapsulated doxorubicin formulation (NK911) with improved tumour penetration and reduced in vivo toxicity is in trial [30]. Liposomal drug delivery system for co-delivery of antagomir-10b (anti-metastasis) and PTX (anti-cancer) was developed to delay 4T1 tumour growth and reduce the lung metastases of breast cancer [31]. A significant inhibition and reduction of $82 \%$ in the tumor growth was observed with PEG coated PTX nanocrystals targeting nude mice (MDA-MB-231/luc) and a lung tumour metastasis model [32]. Much higher i.e. 87\% inhibition of breast tumor growth was reported in xenografted mice (MDA-MB-231 cells) by lipid-conjugated estrogenic (bioactive; 47.03\%) NPs in combination with cisplatin [33]. So far, paclitaxel and irinotecan loaded liposomes known as EndoTAG-1 and MM-398 reached the way to clinical studies in TNBC patients [34].

\section{Micelles:A miracle ball in cancer therapy}

Micelles are colloidal particles (5-100 nm) with a hydrophobic core formed from Van-der Waals bonds and stabilized by hydrophilic shell [35]. Owing to its amphiphilic nature, micelle can deliver both water soluble and hydrophobic drugs for cancer therapy. Taurin et al [36] synthesized a micellar system using styrene-co-maleic acid (SMA) to deliver a hydrophobic curcumin derivative i.e. RL71 for TNBC treatment and showed higher toxicity to cancer cell due to endocytosis mediated higher cellular uptake and slow release profile (Table 1). Although, above strategy enhanced the drug uptake but it lacks specificity which is still a serious challenge in the treatment of metastatic TNBC. Utilizing the concept of specific ligand-receptor interaction and the fact that cetuximab (human chimeric monoclonal antibody) targets the epidermal growth factor receptor (EGFR) over-expressed in TNBCs, Kutty and Feng et al [12] developed cetuximab-conjugated micelles of vitamin E D-alphatocopheryl polyethylene glycol succinate for the targeted delivery of docetaxel drug (Fig. 1) (Table 1). In-vitro experiments in high EGFR expressing TNBC cell line (MDA MB 468), with different formulation of micelles showed the $\mathrm{IC}_{50}$ of $0.1715 \mu \mathrm{g} / \mathrm{ml}$ for TPGS micelle with cetuximab, in comparison to $\mathrm{IC}_{50}$ of 1.12 and $35.26 \mu \mathrm{g} / \mathrm{ml}$ respectively for TPGS micelle without cetuximab and free drug. These results have a promising utility in TNBC treatment subjected to further clinical trials and could be explored as theranostics. A classic example of theranostic and its application in cancer medicine is given by Muthu et al [37] where they developed TPGS micelle conjugated with ligand transferrin which mediated co-delivery of therapeutic docetaxel (drug) and diagnostic nanoclusterAuNc (imaging) for simultaneous detection and treatment in transferrin receptor expressing MDA-MB-231-Luc breast cancer in vitro model. Real-time imaging and tumor inhibition were imaged in xenograft model using above delivery system. Poly (acrylic acid)-g-PEG i.e. PAA-g-PEG copolymeric micelles carrying DOX (50 wt/wt \%) was developed by Sun et al [31] for the efficient reduction in lung metastasis and 4T1 mouse breast tumor growth. However, the only miracle micelle that entered the phase-II clinical trials in TNBC patients is SN-38 (irinotecan) carrying poly(ethylene-glycol)-poly(glutamicacid) PEG-PGlu i.e. NK012 micelle [38] and this needs to be validated in other phases of clinical trials.

\section{Dendrimers: A nanovehicle for siRNA delivery}

Dendrimers are synthetic macromolecules $(10 \mathrm{~nm}$ to 100 $\mathrm{nm}$ ) prepared by either divergent or convergent synthesis of branched monomer. Like liposomes, it presents a cavity-enriched spherical shape with a hydrophobic core and hydrophilic periphery, making them a unique vehicle for siRNA delivery [13, 39]. Wang et al.,[40] demonstrated reduction in tumor vascularization in TNBC xenograft mouse model using antisense oligo (AODNs) conjugated 
Table 1 Targeted and drug delivery system: Liposomes, Micelles, Dendrimers, Polymeric NP and DNA nanostructure are the few delivery systems used to carry different therapeutic drugs like paclitaxel, doxorubicin and docetaxel in addition to tracking dye Cy3 as in DNA nanostructure for the precise and targeted delivery using the target specific ligand cetuximab

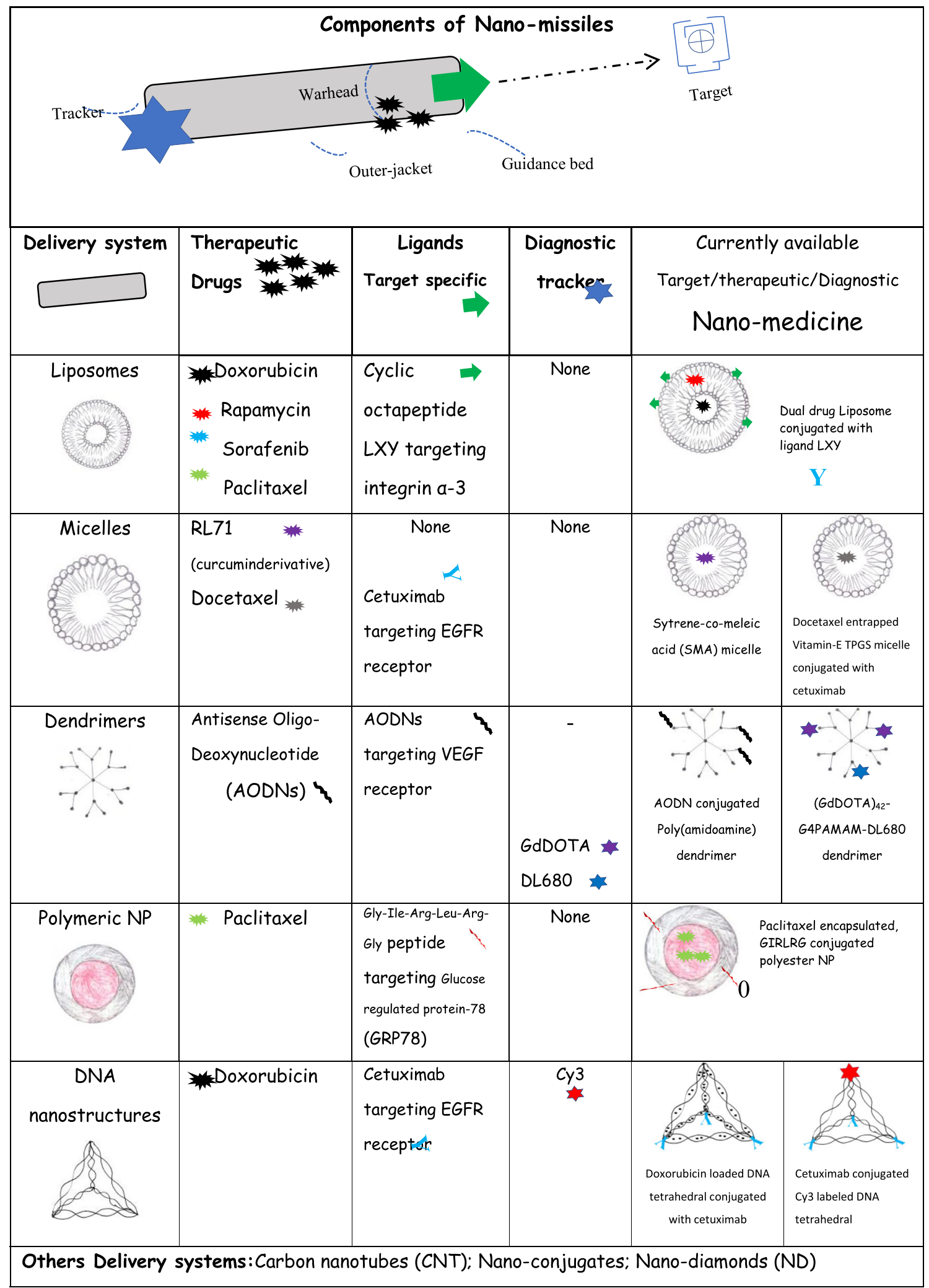



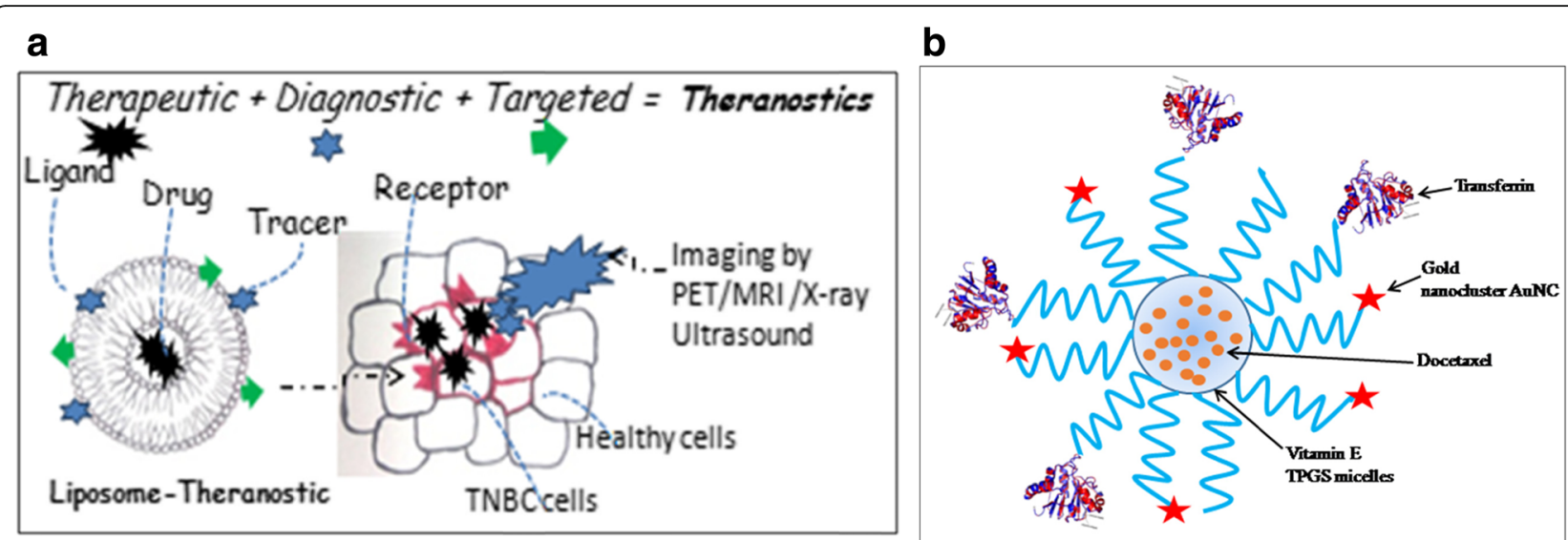

Fig. 1 Diagrammatic representation of the concept of targeted theranostics: a Liposome cavity is loaded with the anti-cancerous drug and the surface of the liposomal nanoparticle is coated with ligand for the targeted and specific delivery of the drug. In addition to this, tracer helps in the accurate screening and diagnosis of cancer cells. $\mathbf{b}$ Transferrin is conjugated to vitamin-ED-alpha-tocopheryl polyethylene glycol succinate (TPGS) micelle for targeted co-delivery of therapeutic drug (docetaxel) and diagnostic agent (AuNC) as theranostic.

poly(amidoamine) dendrimers. This targeted therapeutic approach utilizes the higher expression of vascular endothelial growth factor (VEGF) as receptors of AODNs (Table 1). In another targeted therapy, utilizing siRNA conjugated poly(amidoamine) dendrimer, Finlay et al., [41] have shown the down-regulation of a promising TNBC target i.e. TWISTItranscriptor factor. Dendrimer was also assessed as a targeted diagnostic module by Zhang et al [42] in TNBC tumor mice model. A novel dendrimer G4PAMAM conjugated with GdDOTA (MRI contrast) and DL680 (NIR dye) was prepared and injected subcutaneously in mice as a dual model for imaging and drug delivery (Table 1). MRI scan and near infra-red (NIR) fluorescence imaging showing homing of nanoparticles and higher fluorescence signal respectively in the TNBC tumor, demonstrated targeted diagnostic application of this small sized (GdDOTA) ${ }_{42}$-G4PAMAM-DL680 dendrimeric agent.

\section{Polymeric nanoparticles: A misnomer nanoparticle for cancer treatment}

Polymeric nanoparticle $(50 \mathrm{~nm}-10 \mu \mathrm{m})$, if up to $10 \mathrm{mi}-$ crons in size; can be classified as misnomer nanoparticle. With an additional advantage of encapsulating drugs and proteins without chemical modification, these nano-particles can be prepared from natural or synthetic polymer. Owing to the biocompatibility and reduced toxicity property, biodegradable polymeric particles viz. poly(lactic) and copolymer like poly(lactide-co-glycolide) are being in application for nanoparticle synthesis [43]. Drug molecule could be efficiently encapsulated by the method of nanoprecipitation, electrospray and emulsification; however, $\mathrm{Xu}$ et al [44] developed a novel approach known as PRINT for the synthesis of uniform sized polymeric nanoparticle. PRINT i.e. particle replication in nonwetting templates method provide room for properties customization for effective cancer therapy. Non-targeted delivery of Pt (IV) mitaplatin drug using PLGA-PEG i.e. poly-D, L-lactic-co-glycolic-acid block-poly-ethylene-glycol nanoparticle, showed higher degree of tumor inhibition in in-vivo TNBC mice model (nude mice with MDA MB 468 TNBC cells) [45]. Passarella et al.,[46] identified a novel peptide (Gle-Ile-ArgLeu-Arg-Gly) which specifically recognizes glucoseregulated protein (GRP78) (Table 1). Using irradiated TNBC xenograft mice model expressing GRP78 receptor; this group precisely reported apoptosis at the tumor site by target specific GIALAG-conjugated paclitaxel encapsulated polyester nanoparticles. In a recent clinical trial, 33\% response rate was observed in $90 \%$ of the pretreated metastatic TNBC patients expressing high protein Trop-2 with IMMU-1322 drug (anti-Trop-2-SN-38 antibody) [47]. Succinobucol with P188 (poloxamer) combination are emerging as a best oral treatment for breast cancer. Better bioavailability (13 fold) of succinobucol NPs enhances the inhibition of vascular cell adhesion molecule-1 (VCAM-1) invasion and tumor cell migration [48]. Polymeric NPs are also known to deliver miRNA and siRNA along with therapeutic drug to reduce the tumor volume and ultimately tumor growth. PLGA-bPEG polymer NPs co-delivered both antisense-miR-21 and antisense-miR-10b with $0.15 \mathrm{mg} / \mathrm{kg}$ drug dose whereas siRNA (multidrug resistance protein) and DOX co-loaded NP caused overall reduction in tumor growth and volume (8-fold decrease) respectively $[49,50]$.

A promising ligand, Arg-Gly-Asp (RGD), either facilitates targeted delivery of drug or inhibits invasion of cancer differently in TNBC tumor models. For instances, cyclic RGD-functionalized solid lipid NP (RGD-SLN) shown to inhibit adhesion and invasion of alphavbeta $3(\alpha v \beta-3)$ 
integrin receptor over-expressed in invasive TNBC tumors [51]. This is the perfect example of ligand targeting and inducing inhibition simultaneously in breast cancer cell. Similarly, Zhang et al., [52] synthesized hybrid shealth polymerlipid nanoparticles (PLN), conjugated to peptide ligand RGD and co-loaded with doxorubicin (DOX) and mitomycin $C$ (MMC) i.e RGD-DMPLN. The targeted therapeutic efficiency of RGD-DMPLN was assessed in metastatic TNBC mouse model developed using MDA-MB-231-lucD3H2LN cell line. Enhanced cytotoxicity in both above models was achieved by the virtue of DOX-MMC synergism which further enhances by the target RGD-DMPLN. This type of targeted delivery of synergistic drug enhances the overall efficacy in cancer treatment and need to explore more for wider application in breast cancer.

\section{DNA nanostructures in cancer therapy: DNA beyond coding secrets of life}

DNA nanostructures utilize the most fundamental property of DNA i.e. Watson-Crick complementary nucleic acid base pairing to design different nanostructure like tetrahedral, bipyramids, cages, and cubes with desired shapes, sizes and configuration. These DNA nanostructures can incorporate ligands and/or small functional compounds for site specific attachment and/or for bioimaging. Kutty et al., [27] designed a novel self-assembled DNA nanopyramid, tagged with red-emissive glutathioneprotected gold nanoclusters (GSH-Au NCs) at the base and actinomycin (AMD) incorporated in the DNA minor groove. This theranostic DPAu/AMD so far developed for detection and killing of Escherichia coli and warrant evaluation and modification for other disease/cancer. One of the major challenges utilizing these structures is to escape the endosome degradation of DNA nanostructure in mammalian TNBC. However, same group developed another nanostructure, i.e. DNA tetrahedral (TH) for biosensing and antibody-mediated targeted drug delivery. DNA tetrahedron self-assembled to form four vertices. Cetuximab conjugated $\mathrm{TH}\left(\mathrm{THC}_{3}\right)$ with intercalated doxorubicin (DOX) drug i.e. $\mathrm{THDC}_{3}$ (Table 1) showed preferential killing of MDA-MB-468 cancer cells, due to cetuximab which is known to target EGFR overexpressing cancer cells. Low $\mathrm{IC}_{50}$ value of $\mathrm{THDC}_{3}$ i.e. 0.91 $\mu \mathrm{M}$ in comparison to free DOX i.e. $3.06 \mu \mathrm{M}$ signifies the high and specific killing efficiency of $\mathrm{THDC}_{3}$ [16]. Another modified formulation carrying one $\mathrm{Cy} 3$ probe and three cetuximab i.e. $\mathrm{Cy} 3-\mathrm{THC}_{3}$ shows high signalling intensity due to increased uptake of Cy3$\mathrm{THC}_{3}$ into MDA-MB-68 cells. These two (THDC 3 and $\mathrm{Cy} 3-\mathrm{THC}_{3}$ ) slight modifications of $\mathrm{TH}$ show enhanced targeting and killing of cancer cells which could be an excellent candidate for cancer nanomedicine especially for TNBC.

\section{Metal nanoparticles: Multifunctional smart hard materials for cancer therapy}

In addition to above discussed nanoparticles, metallic NPs such as gold $(\mathrm{Au})$, silver $(\mathrm{Ag})$, platinum $(\mathrm{Pt})$, zinc $(\mathrm{ZnO})$, titanium dioxide $\left(\mathrm{TiO}_{2}\right)$ and many others are used in cancer medicine. These nanoparticles may offer wide opportunity in therapeutic and diagnostic assay due to their magnetic, optical, thermal and electrical properties. Surface modification by conjugating different groups on metal NPs expands the utility for desired clinical outcomes. Different metal NPs utilizes diverse molecular mechanism like production of intracellular reactive oxygen species (ROS), increasing oxidative stress and specific apoptotic tumor cell death [53]. NPs from the transition class of metals induce hyperthermia (noninvasive method), to heat up the cells, thereby killing the tumor cells by converting electromagnetic radiations to heat. Few metal NPs have inherent potent anti-cancer activity owing to their unique physiochemical properties.

Gold nanoparticle (AuNPs) is the most extensively investigated and promising metal NP known to deliver paclitaxel, a widely known anti-cancer drug. Au NPs designed and synthesised in different shapes and configurations as Au-nanoshells (AuNS), Au-nanorods (AuNR) and $\mathrm{Au}$-nanocages (AuNC) are now emerging as a versatile nanovehicle for cancer therapy. PEG coated Au NP in addition to ionizing radiations provided higher survival rate in mice model of breast cancer [54]. Serumcoated AuNR have inherited ability to down regulate the energy generation-related genes expression. Due to reduced energy, migration and invasion of cancer cell is inhibited in both in-vitro and in-vivo. Andey et al.,[33] also showed the inhibition/suppression of the TNBC tumor and metastasis using the combination of cisplatin loaded AuNR and NIR laser. Silver nanoparticles (Ag NPs) are known for its antiproliferative, proapoptotic, and anti-angiogenic effects on cancer cells. As a radiosensitzing agent, AuNPs reacts with acidic environment in cancer cells and increases oxidative stress by the production of ROS which eventually induce damage and apoptosis. Liu et al.,[55] observed promising results of AgNPs treatment followed by radiotherapy on gliomas. These NPs also observed to inhibit endothelial growth factor (VEGF) on cancer cells thus limiting the metastasis. Zinc oxide nanoparticles ( $\mathrm{ZnO} \mathrm{NPs}$ ) function like genotoxic drugs for cancer treatment. ZnO NPs form micronucleus inside the tumor cell, which finally increase mitotic and interphase apoptosis death of the cell [56]. Asparaginase is a well-known anticancerous enzyme used as a chemotherapeutic agent in other cancer treatment, so $\mathrm{ZnO}$ NPs carrying asparaginase, further increase the specificity and stability when given in combination with paclitaxel and daunorubicin [57]. Even, $\mathrm{ZnO}$ NPs in combination with drugs paclitaxel and cisplatin 
shows reduced toxicity and increase efficacy in breast cancer cells [58].

Other metal NPs viz. copper (CuO NP), iron-oxide $\left(\mathrm{Fe}_{2} \mathrm{O}_{3}\right)$, silica, cerium oxide and titanium oxide are also being explored and used in breast cancer diagnosis and treatment. Copper oxide NPs (CuO NPs) are described as green NPs as they were synthesized from Ficus religioss and Acalypha indica. Metastatic lung tumors of mouse (B16-F10 cells) are treated using $\mathrm{CuO}$ NPs by the mechanism of apoptosis and ROS generation [59]. Dual modal therapy employing photodermal and radiotherapy with $\mathrm{Cu}$-64 labelled copper sulfide NP (CuS NP) showed the suppression of tumor growth in subcutaneous BT474 breast cancer model and prolonged the survival of mice bearing orthotopic 4T1 breast tumors [60]. Human breast carcinoma cells (in-vitro) and HER2+ breast carcinoma cells are specifically targeted by anti-HER2 antibody conjugated silica-gold nanoshells in photothermal therapy. Cerium oxide NPs (CNPs) function as a radiosensitizing agent thereby increases the oxidative stress and apoptotic tumor cell death by following the biological mechanism of DNA damage [61]. CNPs also supplement the conventional chemotherapy by delivering chemotherapeutic drugs like DOX, which provide a smart approach for cancer therapy. In addition, platinum and titanium-based NPs are also perceived as a promising nano-carriers and therapeutic candidate in cancer photodynamic therapy respectively. An iron-oxide nanoparticle $\left(\mathrm{Fe}_{2} \mathrm{O}_{3} \mathrm{NPs}\right)$ explores the magnetic property for accurate diagnoses and targeted treatment of cancer as in squamous cell carcinoma mouse model [62]. A multivalent pseudopeptide (N6L) and doxorubicin (DOX) conjugated to $\mathrm{Fe}_{2} \mathrm{O}_{3}$ NPs (MF66) forming a multifunctionalised $\mathrm{Fe}_{2} \mathrm{O}_{3}$ NPs known as MF66-N6L-DOX. This system by combining both hyperthermia and drug delivery module, presented a better specificity and tumor killing potential in breast cancer model (athymic nude mice )[63]. Diagnosis of micrometastasis $(0.5 \mathrm{~mm}$ dia) and metastatic breast cancer in transgenic mouse model are improved by cRGD conjugated Fe2O3 NPs and anti-neu receptor $\mathrm{MAb}$ conjugated superparamagnetic iron oxide NPs (SPIONs) respectively [64, 65]. Finally, trastuzumab conjugated modified magnetic polymerosomes named as herceptin is in clinical trials which can target bone metastasis in a HER2+ breast cancer model (BT474) of NOD/SCID mice.

\section{Carbon nanotubes (CNTs): Folded grapheme for cancer therapy}

Carbon nanotubes (CNTs) are benzene ring knitted flat sheets, folded to form single and/or multi-walled cylindrical structures. Slight chemical modification imparts multiple functions with the huge possibility in cancer therapy. Single walled NTs (1 nm-2 nm diameter) having the ability to penetrate inside cells shows prolonged distribution and localized effects. Oxidized multi-walled carbon nanotubes (o-MWNTs) present a novel approach in cancer therapy, by reducing macrophages and vessel density in the tumor [35, 66]. Burke et al., [67] conceptualize the fact that by hyperthermia, NT promotes cell membrane permeabilization resulting in tumor mass destruction. So, he proposed photo-thermal-induced ablation using multiwalled NT for TNBC therapy. A complex of nanodiamond and DOX known to inhibit cancer in mouse model by overcoming drug efflux and increasing apoptosis [68] and lung metastasis of breast cancer [69].

\section{Ligands for targeted TNBC therapy}

Ligands are the small stretch of nucleotides, peptide or small molecules itself which bind specifically to its receptor by ligand-receptor interaction. Few of the ligands were already discussed in the section 3 . However other like aptamers, antibodies, peptides and other small molecules like carbon and quantum dots are also widely known ligands usedfor targeted or probe based diagnostic in cancer nanomedicine (Fig. 2).

\section{Aptamers: Nucleic acid-based ligands}

Aptamers are short oligonucleotides stretches of singlestranded DNA/RNA. Owing to unique 3D confirmation of aptamer, it specifically binds the target molecule with high affinity and strength. The only limitation is the degradation by nucleases; however, its high stability gained attention for the development of molecular probes. $L i$ et al.,[70] in their preliminary study, specifically target a surface membrane protein on TNBC tumor by newly identified LXL-1 aptamer using cell-SELEX method. Differential overexpression of platelet derived growth factor (PDGF) receptor in TNBC cell line was detected by Huang et al.,[71] using PDGF-aptamer conjugated to gold nanoparticles. MCF7 and MDA-MB-415 breast cancer cells known to over express the mammaglobin A2 and mammaglobin B1. Hassann et al.,[72] detected the metastatic breast cancer by MAMA2 and MAMB1 aptamers using highly sensitive terahertz $(\mathrm{THz})$ chemical microscopy (TCM) using $\mathrm{THz}$ radiations. Another 26mer G-rich DNA aptamer specifically target the nucleolin receptor in some breast cancer cells [73]. However, such aptamer based precise targeted diagnosis still need to be improved and combined with drug delivery for TNBC theranostic application.

\section{Antibodies: $Y$ shaped key with dual functionality}

Antibodies are Y-shaped protein with two epitopes, which has high selectivity and affinity for its receptor. These are rated as the best class of targeting ligands. The utility of antibodies in cancer diagnosis surpasses its high production costs. Conceptualizing the differential up-regulated 


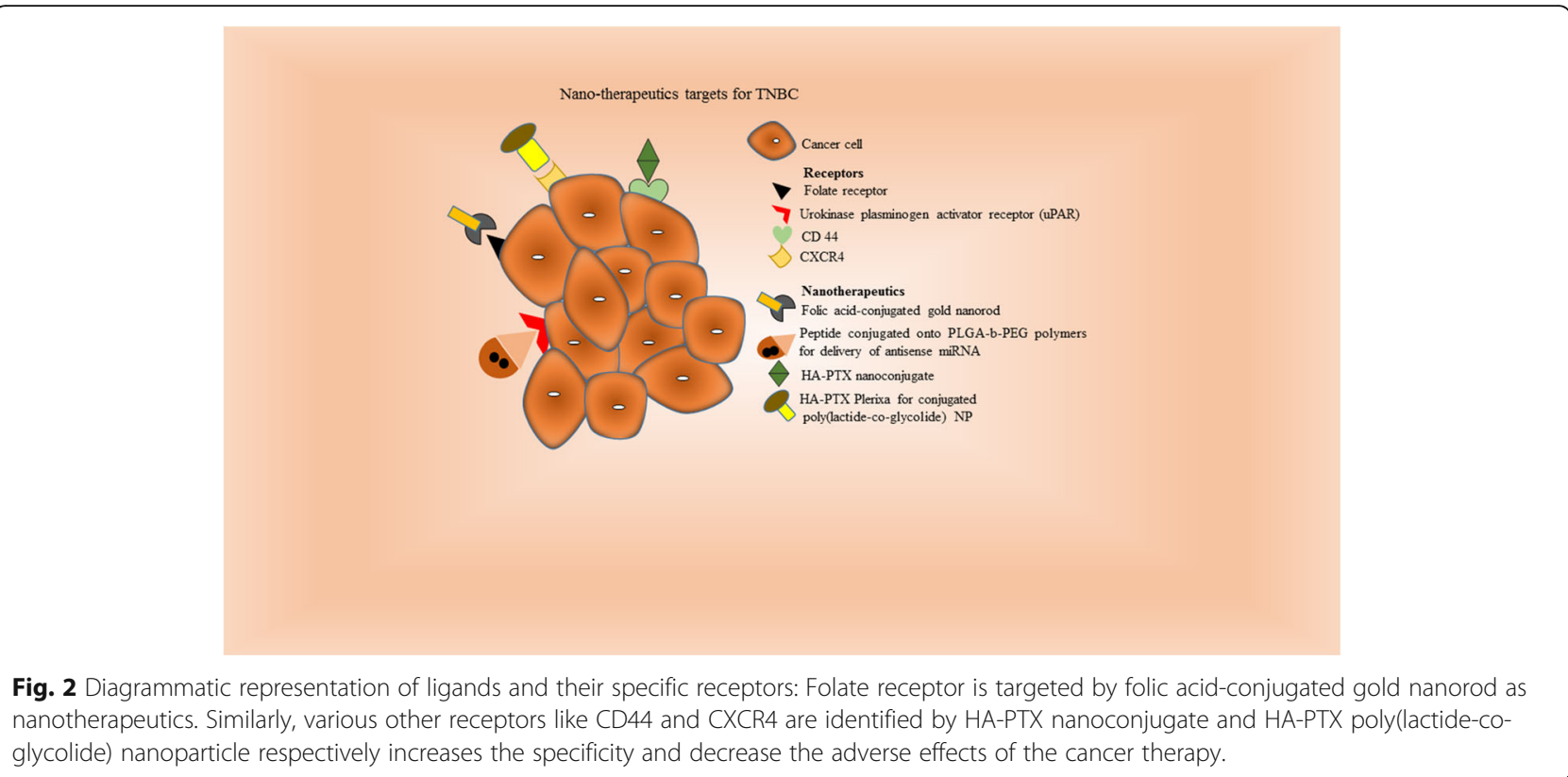

expression of tissue factor (TF) receptor and urokinase plasminogen activator receptor (uPAR) in TNBC, Shi et al., [74] suggested and validated the application of the anti-TF antibody labeled with copper-64 (anti-TF-antibo$\mathrm{dy}^{-64} \mathrm{Cu}$ ) using PET imaging in in-vitro TNBC model. Le Beau et al.,[75] detected NIR fluorophore and Indium-111 $\left({ }^{111}\right.$ In) labelled uPAR antibodies using optical and SPECT imaging respectively. Similarly, anti-EGFR and antiVEGFR antibodies conjugated with fluorescent NP and ultrasound contrast agents are detected using fluorescence microscopy and ultrasonography. Preclinical study on TNBC xenograft mice by Rousseau et al., [76] demonstrates good visualization of TNBC tumor with Iodine-124 $\left({ }^{124}\right.$ I) labeled B-B4 antibody (targeting syndecan-1; CD138 antigen) and experience good response (treatment) with I$131\left({ }^{131} \mathrm{I}\right)$ radiolabelled B-B4 antibody.

\section{Peptides: Cell penetrating ligands as diagnostic/imaging sequences}

Peptides are low molecular weight ligands with an ability to target intracellular molecules with high specificity [77]. These target binding peptides sequences can fuse to bacterial coat proteins and expressed using genetic engineering which are finally screened by phage display library technique [78]. Few peptides for targeting metastatic breast cancer are RGD, P-selection, tumor metastasis targeting (TMT), and chlorotoxin. Feng et al., [79] observed binding of CK3 peptide (Cys-Leu-Lys-Ala-asp-Lys-AlaLys-Cys) to NRP-1 trans-membrane protein (neuropilin1) by NIR fluorescence imaging in breast cancer of TNBC mice models. Activable cell-penetrating peptide (ACPPs) which targets the matrix metalloproteinase (MMP)-2 enzymes, when covalently linked to cyclic-RGD peptide, resulted in enhanced tumor uptake and contrast imaging in in-vivo TNBC models [80]. Modified $\mathrm{Fe}_{2} \mathrm{O}_{3}$ NPs linked to cyclic RGD peptide resulted in superior and efficient targeting of $\alpha v \beta 3$ integrin receptors [81]. Even the dual ligand (P-selectin and RGD-peptide) linked liposomal NP can capture different tumour sites over expressing their respective receptors on the breast cancer cells [82]. Difference in $\mathrm{pH}$ exploited using $\mathrm{pH}$ low insertion peptide (pHLIP). Ali et al.,[83] designed a $\mathrm{pH}$-responsive MRI nano-probe i.e. pHLIP-conjugated MRI-NP which specifically internalize and accumulate in in-vitro TNBC cells in response to its low $\mathrm{pH}$.

\section{Other small molecules}

These ligands $(<500 \mathrm{Da})$ are the potential targeting agent for cancer imaging. The most widely clinically accepted molecule is ${ }^{18}$ F-FDG which is a glucose analogue [84] while other molecule like folate has potential as direct imaging agents. Meier et al., [85] shows that folate molecule drives super-paramagnetic iron oxide contrast agent (P1133) to folate receptors and internalized in the actively growing TNBC in both in-vitro and in-vivo system. Even folic acid conjugated AuNR target the folate receptor and showed enhanced uptake in $4 \mathrm{~T} 1$ metastatic breast cancer cells [86]. Carbon dots (CDots) and quantum dots (QDs) are useful in biomedical imaging [87] and holds great promise for early stage TNBC detection. Chemokine receptor type 4 (CXCR4) is a cellular target involved in the growth and metastasis of TNBC. Plerixafor or AMD3100 (CXCR4 ligand) conjugated poly(lactide-co-glycolide) NPs enhanced siRNAmediated gene silencing by improving the cellular uptake into MDA-MB-231 cells [88]. Similarly, AMD3100 
loaded human serum albumin encapsulated NPs targets CXCR4 on lung metastatic model of breast cancer [89]. Hyaluronic acid (HA) has high affinity to CD44 receptor therefore an ultra-small ( $\sim \mathrm{kDa})$ HA-PTX nanoconjugate are taken up via $\mathrm{CD} 44$ receptor-mediated endocytosis into metastatic breast cancer (MDA-MB-231Br) cells [90]. Urokinase plasminogen activator receptor (uPAR) targeting peptide conjugated to poly (lactic-co-glycolic acid)-b-PEG polymers carrying two antisense miRNA showed significantly higher tumor inhibition using [49]. Functionalized fullerenes have been used as novel contrast agents in MRI. Other small carbon molecules like nanocarbons, nanodiamonds with distinctive physical and chemical properties are also emerging in biomedicine $[91,92]$ and needs to be extensively studied.

\section{Virus like particles (VLPs) as novel nano-vehicles and future theranostics}

Virus-like particles (VLPs) are self-assembled multimeric nanostructure $(0.1-100 \mathrm{~nm})$ produced by the expression of viral structural genes in heterologous systems. The notion of virus-like to VLP is because they are free of any viral genetic material; and this makes them a versatile nanovehicle for drug delivery. VLP can be from microbial, plant or mammalian virus origin and assembled into spherical and filamentous [93]. Modified VLPs with foreign ligands is produced by expressing required heterologous peptides/proteins/gene sequence on the surface (capsomers). Also, chemical modification of the functional groups contained in the structural capsid protein aids targeted mediated therapy. Most remarkable attribute of VLPs are its small size enough to move in the blood stream and functional viral proteins on cell surface which facilitates cell entry/penetration inside the cell. The ability of VLP to encapsulate small molecules/drug may be applicable for cancer treatment by targeting and entering the specific tumor cells by energy-using receptor-mediated endocytosis and finally, liberating the encapsulated drug inside the cancer cell. Most astonishing ability is to escape the endosomes before lysosomal degradation; this favors the drug availability and protect drug in blood plasma. The only limitation with the use of VLP as drug delivery system is that it elicits innate immune response due to viral proteinaceous particle and readily up taken by dendritic cells [94], however on failure of classical chemotherapy, it gave an optimistic hope for TNBC treatment. Also increase in drug bioavailability and biocompatibility may compensate the above disadvantages. Various VLPs are derived from Human papiloma virus (HPV), Bacteriophage, Polyomavirus, Ebola, Influenza, Hepatitis E virus (HEV) [95] and Tobacco mosaic virus (TMV). Some VLPs display natural tropism to certain organ or tissues like HEV VLPs for liver/hepatocytes, however majority of the VLPs display tropism to sialic acids or heparin sulphates limits its use as a targeted nanocarrier. A classic example of VLPs as targeted therapeutic carrier is self-assembled Bacteriphage MS2 VLP, which is modified with SP94 peptide and encapsulated with doxorubicin/cisplatin/ and 5-fluoro-uracil to selectively deliver and kill human hepatocellular carcinoma (HCC) in Hep3B cell line [96]. Rotavirus shows natural tropism towards the gut. These concepts utilize by Cortes et al.,[97] to develop rotavirus VLP which successfully enter (in-vivo) and deliver green fluorescent protein (GFP) in intestinal cells of healthy mice. Adenovirus (Ad3) derived VLP, dodecahedron chemically conjugated with anticancer antibiotic Bleomycin (BLM), Db-BLM induce death of transformed cells by causing ds-DNA breaks with lower concentration [98].

So, the popularity of VLPs is attributed by its versatility, cell-specific targeting, and efficient cell entry, lack of endosomal sequestering, multivalency, biocompatibility, large encapsulation and safe delivery system. Despite so many advantages, VLPs as drug delivery system are in their infancy and need to be validated on animal model.

\section{Need of nanomedicine for breast cancer therapy: Shift from conventional to nanomedicine}

Conventional chemotherapeutic agents unfortunately associated with many limitations. Non-specific target resulting in systemic toxic effects, adverse clinical outcomes, toxic to rapidly dividing normal cells leading to chronic toxicity including very common manifestation like alopecia, mucositis and thrombocytopenia. Poor solubility and low bioavailability in addition to drug resistance due to possible mechanism involving overexpression of P-glycoprotein and mutated topoisomerase II further restricts the usefulness of anticancer agent. Even the tumor/cancer cells structural makeup limits the clinical outcomes due to poor penetration of drug because of physical barriers, intercellular junctions controlling drug permeation, and extracellular matrix proteins [99]. Current problem in cancer therapy is the rapid drug clearance and limited targeting, which necessitates the emergence of nanomedicine in treating cancer. Breast cancer primarily metastasizes to the regional lymph nodes, bone and lungs; however, metastatic breast cancer has spread to distant sites. Aggressive proliferation, heterogeneity and resistance of tumor to therapeutics are few challenges in treatment of metastatic breast cancer. Adjuvant therapy including chemotherapy (paclitaxel, eribulin), hormone therapy (letrozole, tamoxifen) has various longterm side effects affecting the patient's quality of life [100]. So far, no targeted therapy in clinic for treating triple negative, resistant and recurrent breast cancer. Moreover, TNBC lacks ER, PR and Her-2 /neu and are also difficult to treat, therefore most likely to recur and disseminate. With characteristic short overall survival and increase risk of metastasis, its treatment remains a challenge. So, chemotherapy remains the only option for TNBC treatment with 
anthracyclin and taxane based chemotherapy and neoadjunant chemotherapy option $[6,101]$. Despite comprehensive and aggressive management, 50\% reoccurrence with 37\% mortality necessitate the advanced, novel and effective therapy [102]. Therefore, multifunctional smart nanoparticles conjugated with targeting, therapeutic, fluorophore can cross different biological barriers, target and penetrating cancer cells by passive method known as enhanced permeability and retention (EPR) effect, and finally release drug in the cancer cells in a controlled manner.

\section{Novel breast cancer drugs in useor in clinical trials}

For the treatment of TNBC, many potential agents are under different stages of research and development. These potential agents/inhibitors have different specific targets and execute its anti-tumor activity differently [103]. A brief summary on different classes of inhibitors like poly (ADP-ribose) polymerase (PARP), tyrosine kinase (TK), EGFR, PI3K, angiogenesis, insulin-like growth factor (IGF), heat shock protein (Hsp90) and histone deacetylase (HDAC), mammalian target of rapamycin (mTOR), and the mechanism of their action shown in Fig. 3. Briefly, Poly (ADP-ribose) polymerase inhibitors (PARPI) target ssDNA break repairing enzyme causing synthetic lethality [104]. Various PARPIs like olaparib, veliparib, talazoparib have been evaluated in clinical trials on TNBC patients. Olaparib for BRCA-mTNBC is undergoing phase III (OLYMPIAD; NCT02032823) trial will likely to be completed in March 2020. Olaparib in combination with paclitaxel, cisplatin induced overall response rate of $88 \%$ [105]. Receptor tyrosine kinase (RTK) inhibitors targets in TNBC are EGFR, FGFR, VEGFR and MET. EGFR expressed in $89 \%$ of TNBC and appears a promising therapeutic target, but surprisingly majority of the EGFR-TKIs trials against TNBC are not promising [106]. FGFR as a therapeutic target in only $\sim 10 \%$ TNBC emerged recently, therefore pan-FGFR inhibitors PD173074 and alofanib inhibits the proliferation of SUM52PE and induce apoptosis by inhibiting MAPK and PI3K signalling cascades [107]. VEGF expression are associated with poor prognosis in TNBC, however the clinical trials with bevacizumab and apatinib targeting VEGF2 do not produce promising results [108]. Contrary to this, sunitinib, anti-VEGFR tyrosine kinase inhibitors are emerging as a potential therapeutic candidate in breast cancer trials. MET is a TNBC cell surface RTK which activates multiple downstream effectors including Src, AKT, ERK and RAS. Phase II trial of the tivntinib (MET inhibitor) is disappointing, however MET+EGFR inhibition synergistically reduced cell viability, highlighting the superior efficacy of this combination [109].

Non-receptor tyrosine kinases (NRTKs) are cytoplasmic kinases including PI3-AKT-mTOR signalling cascade, Src, and MEK. Dual mTORC1/2 inhibitors with everolimus, synergistically reduce proliferation of multiple TNBC cell lines. However clinical trials on TNBC

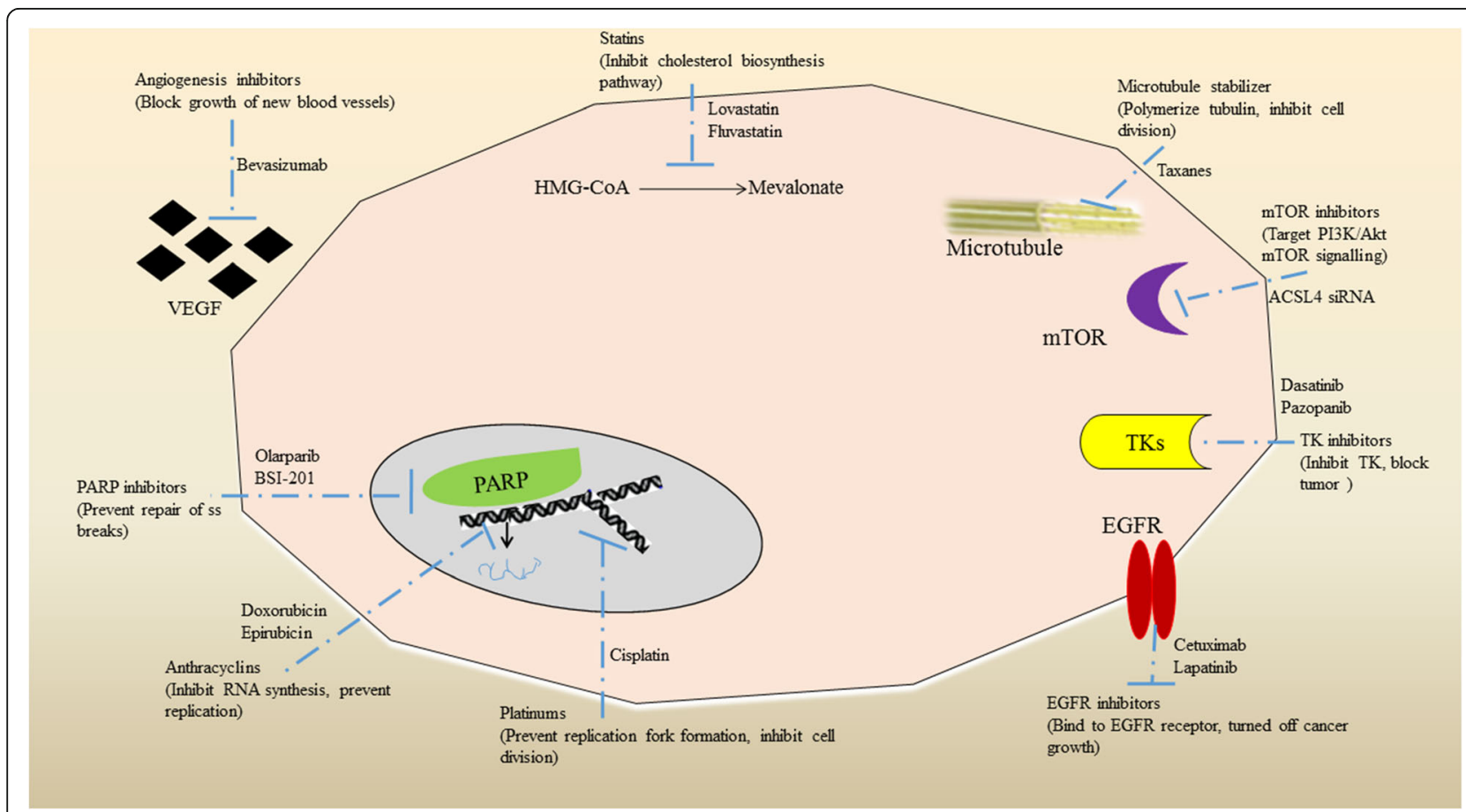

Fig. 3 Brief representation of potential inhibitors of various pathways and receptors for the treatment of triple-negative breast cancer. Poly (ADPribose) polymerase (PARP) inhibitors like BSI-20l target ssDNA break repairing enzyme causing synthetic lethality resulting in control of cancer cell proliferation. Similarly, other class of inhibitors like tyrosine kinase (TK), EGFR, PI3K, angiogenesis, insulin-like growth factor (IGF), heat shock protein (Hsp90), histone deacetylase (HDAC), andmammalian target of rapamycin (mTOR) employ different mechanism to control and treat TNBC. 
with $\mathrm{mTOR}+\mathrm{PARP}$ inhibitors and dual $\mathrm{mTOR} / \mathrm{P} 13 \mathrm{~K}$ inhibitors are ongoing. PI3-AKT-mTOR pathway represents as an emerging multi-target of drugs at early stages of clinical development [110]. MEK is a component of the MAPK signalling cascade where MEK inhibitors (U0126) significantly reduce the invasiveness of MDA-MB-2311 in-vitro whilst lung metastasis is known to be inhibited in xenograft model by selumetinib [111]. Src is a cytoplasmin oncoprotein and addition of Src inhibitors i.e. dasatinib to cetuximab + cisplatin enhanced the inhibition of cell growth and invasion in TNBC [112]. Epigenetic targets like HDACs and Hsp 90 are also being investigated for TNBC treatment. HDACs are known to inhibit the expression of DNA repair genes and tumor suppressor genes. Two clinical trials are investigating HDACi's combined with DNA methyltransferase inhibitors and cisplatin [113]. Hsp90 has the potential to inhibit multiple growths, signalling and survival cascades. Phase 1 clinical trials with olaparib and paclitaxel for evaluating Hsp90 inhibitors are ongoing; however, Ganetespib (Hsp 90 inhibitor) reduced tumor volume in MDA-MB231 derived xenografts [114]. Anti-androgens bicalutamide and enzalutamide, target the androgen receptor (AR) in various TNBC cell lines which further inhibited proliferation, invasion and migration of cancer cells suggested them as a surrogate biomarker for response to other therapies [115].Voltage-gated sodium channel (VGSC) isneonatal splice variant of the VGS subtype Nav1. 5. VGSCinhibiting drugs such as ranolazine, riluzole and phenytoin, all suppress metastatic cell behaviours in vitro and/or in vivo and are the basis of clinical management of TNBC [116]. NP based formulations currently in clinical use for the treatment of metastatic breast cancer are Liposomes-Doxorubicin nanodrug as Lipo-Dox and Myocet was approved in 1998 (Taiwan) and 2000 (EMA) respectively for breast cancer [117]. In 20052008, nanoparticle albumin bound to Paclitaxel as Abraxane and doceaxel (DTX)-polymer NPs (BIND014) [118] were approved for advanced metastatic breast cancer [119]. Similarly, using Paclitaxel as active drug, PEG-PLA polymeric micelle formulation as Genexol-PM was approved by South Korea in 2007 for breast and ovarian cancer. Numerous nanoparticles are being created for cancer treatment, and many of them are liposomal and polymeric nanoparticle platform. Liposomal nanoparticles with mitoxantrone named as plm60-s (Mitoxantrone $\mathrm{HCl}$ liposome injection) are in II phase of clinical trial for breast cancer [120]. LiPlaCisa liposome nanoparticle with cisplatin is in II pahse of clinical trial with the promising results for metastatic breast cancer [121].

Immunotherapeutics: Targeting cancer with immune cells Immunotherapy is a concept of utilizing intrinsic mechanism of host immune system to combat cancer by enhancing immune system to recognize and kill tumor cells. This is a novel and revolutionary discovery by 2018 Medicine Nobel Prize winners Professor Tasuku Honjo (Kyoto University of Japan) and Prof. James P Allison (University of Texas) for using immune checkpoint blockade to treat cancer by inhibition of negative immune regulation. Immunotherapy with recent advances has achieved success and yielded new therapeutics strategy for TNBC treatment [122]. Lack of targets for existing therapies and immunogenic nature of tumor, render them good candidate for immunotherapy. Various immunotherapies have been tested including immune checkpoint blockers, cytotoxic T lymphocytes (CTLs) activation, adaptive cell transfer-based therapy (ACT) and modulation of tumor microenvironment (TME). Such novel immune-modulatory strategies can tackle TNBC and emerged as personalized immunotherapy (Table 2).

\section{Immunotherapy for triple negative breast cancer}

Tumor vaccination comprises of tumor cells or tumor antigen, to stimulate host to produce effective antitumor immune response. This class of vaccine also includes DNA vaccines, anti-idiotypic Ab vaccine, antitumor related pathogen vaccine and dendritic cell vaccine. Tumor cell vaccines are produced from human tumor cells that retain its immunogenicity for better clinical outcome. Belanyenpumatucel-L is an example of allogenic tumor cell vaccine which specifically target TGF-beta-2 receptor [123]. Tumor antigen vaccines are developed by utilizing tumor specific antigen (TSA) and tumor associated antigen (TAA) [124]. A modified tumor antigen vaccine containing $\mathrm{MHC1}$ is known as theratope is in phase III clinical trial. Endocrine therapy and theratope (Sialyl Tn-KLH; Biomira) combination showed slowing down of progression in metastatic breast cancer. DNA vaccine is a bacterium expressed plasmid with DNA encoding antigenic proteins which can elicit $\mathrm{Ab}$ or $\mathrm{CMI}$ response, for example Mammaglobin-A DNA vaccine in phase-I clinical trial for breast cancer treatment $[125,126]$. Among the anti-idiotypic Ab vaccine, Racotumomab is against the surface membrane glycoprotein of NSCLC (Non-small cell lung carcinoma) and need to be explored for TNBC.

Apart from tumor vaccine, T-cell based therapy including adoptive cell transfer therapy (ACT) is the prime strategic response against cancer. ACT involves selftransfer of $\mathrm{T}$ cells, lymphokine-activated killer (LAK) cells, cytokine activated killer (TIL) cells, and macrophages activated killer (MAK) cells in patients to kill tumor cells and improve immune response. Cytokineinduced killer (CIK) cell infusion therapy with adjuvant radiotherapy had significantly prolonged disease-free survival in TNBC patients [127]. Modified approach of ACT is cascade primed immune cell therapy (CAPRI). 
Table 2 Ongoing clinical trials for TNBC: Different class of agents are being tested (eg. Anti-PD1- Pembrolizumab) on different subjects (eg. metastatic TNBC) and given in combination with other chemotherapeutic agents as the promising immunotherapy for TNBC treatment. These trials are approved with identifier and are in different phase of their evaluation with their probable compeltion date

\begin{tabular}{|c|c|c|c|c|c|c|}
\hline Class of agents & Agent & Phase & Participants & Combinatorial agent & Completion & Identifier \\
\hline AR antagonist & Enzalutamide & 2 & Stage I-III AR positive TNBC & - & April 2019 & NCT02750358 \\
\hline Anti-PD1 & Pembrolizumab & $1 / 2$ & Recurrent TNBC, mTNBC & PLX3397 (TKI of KIR, CSFIR) & May 2019 & NCT02452424 \\
\hline Anti-PD1 & Pembrolizumab & 2 & mTNBC & Carboplatin + gemcitabine & June 2019 & NCT02755272 \\
\hline $\begin{array}{l}\text { Hsp90 } \\
\text { inhibitors }\end{array}$ & Onalespib & 1 & $\begin{array}{l}\text { Metastatic solid tumor, Recurrent } \\
\text { TNBC }\end{array}$ & Olaparib & October 2019 & NCT02898207 \\
\hline AR antagonist & Enzalutamide & $1 / 2$ & AR positive $\mathrm{mTNBC}$ & Taselisib (PI3K inhibitor) & $\begin{array}{l}\text { December } \\
2019\end{array}$ & NCT02457910 \\
\hline Anti-PD1 & Pembrolizumab & 3 & Recurrent TNBC and mTNBC & $\begin{array}{l}\text { Nab-paclitaxel/Paclitaxel/ } \\
\text { gemcitabine/ } \\
\text { carboplatin }\end{array}$ & $\begin{array}{l}\text { December } \\
2019\end{array}$ & NCT02819518 \\
\hline PARPi & Olaparib & 3 & TNBC, Germline BRCA1/2 mutation & - & March 2020 & NCT02032823 \\
\hline PARPi & Olaparib & $1 b$ & Recurrent $\mathrm{TnBC}$ & AZD2014 (mTORC1/2 inhibitor) & $\begin{array}{l}\text { November } \\
2020\end{array}$ & NCT02208375 \\
\hline AR antagonist & Enzalutamide & 2 & AR positive $\mathrm{mTNBC}$ & Paclitaxel & $\begin{array}{l}\text { December } \\
2020\end{array}$ & NCT02689427 \\
\hline Anti-PD1 & Pembrolizumab & 2 & Advanced TNBC or mTNBC & - & January 2021 & NCT02644369 \\
\hline Anti-PD-L1 & MPDL3280A & 2 & TNBC & Nab-paclitaxel & February 2021 & NCT02530489 \\
\hline Anti-PD1 & Pembrolizumab & $1 / 2$ & mTNBC & Paclitaxel & May 2021 & NCT02734290 \\
\hline
\end{tabular}

As an adjuvant therapy, cells obtained from peripheral blood having tumor immunogenicity, become T cell and destroy the tumor cells of breast cancer [128]. Chimeric antigen receptor (CAR) can direct $\mathrm{T}$ cells to recognize antigen expression on tumor cells, however CAR therapy is associated with cytokine release syndrome (CRS), B cell aplasia and tumor lysis syndrome (TLS), thereby restricts the utility in cancer treatment [129].

Cytokine therapy treats cancer by multiple ways. The most common way is by elevating cytokines levels, enhancing expression of tumor-related Ag, by stimulating immune effector cells. IL-2 promotes $\mathrm{T}$ cell proliferation and activation of NK, CTL along with B cell proliferation [130]. However IFN- $\gamma$ approved for treatment of renal cell carcinoma, CK therapy would be an attractive area in breast cancer treatment.

Therapeutic antibodies targeting CD3, CD19, CD20, CD22, CD30, CD33, epithelial cell adhesion molecule, VEGF, EGFR, HER2, NF- $\kappa \beta$, CTLA-4, PD- 1 and PD-L1 receptors used as immunotherapeutics. Currently, herceptin and NeuVax vaccine (Immunodominant nanapeptide with GM-CSF) are targeted against HER2-expressing breast cancer. Zoledronate is in clinical phase-II for triple -negative breast cancer treatment [131]. Antibodies like cetuximab inhibiting EGFR; bevacizumab targeting VEGF; rituximab targeting $\mathrm{CD} 20$, and ipilimumab, nivolumab and pembrolizumab immunostimulating anti-CTLA-4, anti PD-1 and anti-PD-L1 respectively are the promising antibodies as immunotherapeutics for TNBC treatment.
Immune checkpoints are protective effector molecules of human immune system. Inhibitors of CTLA-4, programmed death 1 (PD-1) and programmed death ligand-1 (PD-L1) are immune check point blockers. Clinical trials with checkpoint inhibitors in breast cancer have only been recently initiated. CTLA-4/CD152 checkpoints are expressed on CD8 T cell, CD $4 \mathrm{~T}$ cell, Fox P3+ regulatory and NK cells involved in immune activation [132]. Ipilimumab (humanized IgG1MAb) and tremelimumab (human IgG2 MAb) are FDA approved antibodies used as CTLA-4 inhibitors in different cancer treatment which reactivate $\mathrm{T}$ cells and eventually enhance anti-tumor immune response. PD-1 is monomeric glycoprotein/checkpoint receptor, expressed by $\mathrm{T}$ cells surface and binding to PD-1 is blocked by blocker would enhanced $\mathrm{T}$ cell immune response [133]. Nivolumab (humanized IgG4 MAb) and pembrolizumab (humanized IgG4 isotype MAb) are FDA approved PD-1 targeting antibodies whichinhibit PD-1 and shows therapeutic benefit in melanoma and NSCLC in two different phase III trials (Checkmate-057 and Checkmate -037) [134]. Nivolumab is being evaluated as monotherapy in an adaptive phase II trial (NCT022499367) and in combination with TAK-659 (TK inhibitor) in phase 1b (NCT02834247) of metastatic TNBC [135]. Pembrolozumab blocks interaction between PD-1 and PD-L1/PD-L2 and evaluated as monotherapy by screening 111 metastatic TNBC patients in phase 1b (KEYNOTE-012; NCT01848834) trial [136]. Other trials assessing the efficacy and response of pembrolizumab as monotherapy in metastatic TNBC are phase II 
(KEYNOTE-086; NCT02447003) and phase III (KEYNOTE-119; NCT02555657) trials. Combination of pembrolizumab and chemotherapy is also evaluated in randomized phase III (KEYNOTE-355; NCT02819518) trial for metastatic TNBC. Effect of adjuvant treatment with pembrolozumab is also evaluated in phase III (SWOG-S1418, BR006; NCT02954874) trial with 1000 TNBC patients. Higher levels of tumor-infiltrating lymphocytes (TILs) have prognostic significance and suggest immune response to tumor associated antigen in TNBC [137]. PD-L1 expressed on tumor cells exerts inhibitory effect on $\mathrm{T}$ cell and tumor-infiltrating inflammatory cells by interacting with $\mathrm{PD}-1$ receptor on $\mathrm{T}$ cells. Clinically important PD-L1 inhibitors are atezolizumab (IgG1 isotype MAb), avelumab (human IgG1 $\mathrm{MAb}$ ), and durvalumab (IgG1 MAb). Atezolizumab binds selectively to PD-L1 on immune cells/tumor cells and prevent interactions with the $\mathrm{PD}-1$ receptor. A phase I (NCT01375842) trial with fifty-four metastatic TNBC patients [106] to assess the safety profile of atezolizumab and phase 1b (NCT01633970) trial in combination with nab-paclitaxel emerged as attractive chemoimmunotherapy in metastatic TNBC treatment [138]. Combined efficacy of atezolizumab and chemotherapy is evaluated for TNBC in phase III (NCT02620280) neoadjuvant trial. Recently, FDA granted approval to first immunotherapy i.e. Atezolizumab (Tecentriq, Genetech/Roche) plus chemotherapy nab-paclitaxel (Abraxane, Celgen) for the first-line treatment of unrespectable locally advanced or metastatic, PD-L1-positivetriple-negative breast cancer (TNBC) [18]. Atezolizumab plus nanoparticle albuminbound (nab)-paclitaxel synergistically enhance the anticancer activity and prolonged the progression-free survival among patients with metastatic triple-negative breast cancer in both the intention-to-treat population and the PD-L1-positive subgroup (Impassion130; NCT02425891). Velumab is undergoing a phase $\mathrm{Ib}$ (JAVELIN; NCT01772004) trial in a cohort of 168 metastatic breast cancer patients. Another phase III randomized trial (A-BRAVE; NCT02926196) was conducted in 355 TNBC patients with avelumab to evaluate adjuvant treatment. Durvalumab blocks the activation of PD-1 receptor expressed on activated T cells. Various clinical adjuvant therapeutic trials are going with different stage TNBC patients. Phase Ib (NCT02826434) trial for stage II/III TNBC patients include durvalumab with PVX-410 vaccine as adjuvant; however, another phase I/III (NCT02489448) trial with neoadjuvant nab-paclitaxel with doxorubicin, cyclophosphamide and durvalumab in stage I/III TNBC patients. Other targets like lymphocyte activating gene 3 (LAG3) and T cell immunoglobin and mucin-3 (TIM3) are expressed on activating $\mathrm{T}$ cells, NK and monocytes and served for immune checkpoint inhibition [139].

Immuno-interventions are being explored as neoadjuvant therapy against TNBC. Melanoma-associated antigen-3 (MAGE-3) and alpha-lactalbumin antigen are expressed in breast and tested as a tumor vaccine to produce effective anti-tumor immunity. Significant suppression of breast tumor is reported in mice vaccinated with GM-CSF adjuvant alpha lactalbumin vaccine [140]. Allogenic Dendritic cell (DC) fused TNBC vaccine can stimulate $\mathrm{T}$ cell proliferation and produce tumor specific immune response against TNBC, possibly by increasing IL-12 aand IFN- $\gamma$ levels [141]. Many clinical trials of immunotherapy agents are in progress with a hope to change the standard of TNBC care and treatment.

\section{Nanomaterials assisted immunotherapy for TNBC}

Nanotechnology provides efficient and smart nanodelivery systems facilitating the delivery of immunostimulating adjuvants and tumor antigens to enhance antigen presentation and immunity which aids in treatment of metastasis. An improved and clear understanding of TNBC immunogenicity has led several trials with different immunotherapeutic agents, with the hope of developing new immunotherapeutic modalities in TNBC [137, 142]. Approximately, 45 formulations, majority of liposomal NPs containing GM-CSF, anti-TNF- $\alpha$ are approved for clinical use in cancer therapy. Nano-particulate carriers improve solubility and bioavailability of immunotherapeutic and protect them from degradation, therefore enhance potential efficacy.

Nanoparticles (NPs) assist improvement in antigen expression pathways by the delivery of epigenetic modulators and immunostimulator cytokines [108]. NPs mediated transfer of epigenetic inhibitors has been efficacious in initial trials of breast cancer. DOX with decitabine NP (DNMTi) shown to increase the sensitivity of breast cancer cells [143]. Similarly, vorinostat (HDACi) delivered with improved solubility (four-fold), half-life and pharmacokinetics using the poly-ethylene-oxide-polylactic acid (PEO-PLA) copolymer micelles [144]. Cytokines like IL-2, IFN- $\gamma$, TNF- $\alpha$ and thymosin are FDA approved immunostimulator for cancer treatment (renal cell carcinoma). These cytokines directly stimulate NK, CTL and immune effector cells and finally enhance the immune response. Liposomal NPs mediated delivery of cytokines, for example PEG-coated liposomal NPs assisted delivery of IL-2 cytokines has reduced tumor growth [145]. Cytokine therapy in combination with cancer vaccines may able to stimulate and increase effector $\mathrm{T}$ cells, but still more research needs to be done for TNBC nanomedicine.

Tumor micro-environment (TME) is the critical factor which affects the delivery and efficacy of diagnostic and therapeutic modules. NP mediated delivery of soluble 
mediators like TGF- $\beta$ receptor inhibitor broadly increases the number of CD8+ T and NK cells. Other strategy to knockdown TGF- $\beta$ by $50 \%$ in melanoma using liposome-protamine-hyaluronic (LPH) acid NP codelivered with siRNA (TGF- $\beta$ ) and cancer vaccine [146]. Stimulator of IFN gene (STING) resides inside the cell and is becoming an exciting target for cancer therapeutics. cGAMP encapsulated liposomal NPs (cGAMP-NP) penetrates inside the cell for its intracellular delivery. cGAMP-NP directed activation of STING, activate human macrophages to increase IFN- $\gamma$ producing $\mathrm{T}$ Cells which eventually reduce melanoma tumor load [147]. A self-degradable hyaluronic acid (HA) integrated $\mathrm{pH}$ sensitive dextran NP patch which encapsulates PD1 and glucose oxidase (GOx) was developed as immunotherapeutic module by Wang et al.,[148]. In melanoma mouse model (B16F), a strong robust immune response was induced with this novel microneedle patch. CTLs response in cancer therapy is also induce by lipid-calciumphosphate (LCP) NPs mediated transfer of cancer antigen. B16F10 melanoma also treated with lipid NP formulation containing mRNA for gp100 and TRP2, thereby inducing strong cytotoxic $\mathrm{CD} 8 \mathrm{~T}$ cell response resulting in overall shrinkage of tumor in mice [149].

Inherited immunostimulating immunotherapeutic involve metals like selenium (Se) and mica posing inherit immunostimulating properties. SeNPs exhibit its anticancerous activity by stimulating neutrophils, $\mathrm{T}$ and $\mathrm{B}$ lymphocytes and NK cell mediated cytotoxicity [150]. However, the oral and nasal mode of administration is the major drawback of this therapy and needs reevaluation in cancer immunotherapy.

Other nanocarriers facilitating the immunotherapy are liposomes, exosomes and nanospheres. Cationic liposomal NPs with poly (I/C) and peptide emerged as cancer vaccine formulation showing increased $\mathrm{T}$-cell response [151]. Fc receptor targeting tumor peptide vaccine (nano-liposome) with Palm-IL-1/MAP-IFN- $\gamma$ peptide as adjuvant, targets the DCs and produce strong anti-tumor response in cancer patient. Ascetic cell exosomes (small membrane vesicles) also induce production of cytotoxic T-lymphocytes when given with granulocyte-macrophages colony-stimulating factor (GMC-SF) in phase 1 clinical trials [152]. Combined delivery of siMDR1 (multi-drug resistance gene) with DOX using hollow carbon nanospheres facilitates 90\% reduction of tumor weight in mice by downregulating MDR1 protein expression [153]. Even the antigen-capturing nanoparticles (AC-NPs) induce $\mathrm{CD} 8+$ cytotoxic and $\mathrm{CD} 4+\mathrm{T}$ cells population, thereby improving cancer immunotherapy [154].NP carrying bevacizumab and CRLX101 showed good efficacy in TNBC treatment [155]. Polymeric NP based vaccine with IFN-stimulated gene and albumin NPs with
TA99 Mab can turn phagocytes and lifting neutrophils against cancer [156, 157].

Autophagy is known to promote or suppress cancer development (double edge sword), therefore recently explored as immunotherapeutic modality. Autophagy is a genetically well controlled defence mechanism which has been reported to modulate immune system. Sulforaphane (SFN) induce autophagy by down regulating the expression of histone deactylase (HDAC6) mediated phosphatase and tensin homolog (PTEN) activation in MDA-MB-231 and MDA-MB-468 cells which significantly sensitizes TNBC to DOX. Autophagy induction (SFN) in combination with DOX (therapeutic) inhibits tumor growth and may provide an effective approach for TNBC therapy [158]. Autophagy mediated suppression of cancer is promising treatment modality and warrants detailed investigation.

\section{Nanoparticle infiltration: Route from blood vessels to breast tumor site}

Nanoparticles (NPs) with ligands for targeted drug delivery or carrying diagnostic and/or therapeutic (theranostics), or loaded with immunotherapeutic with immunomodulating or immunostimulating anti-cancer affects needs to be injected, circulated in blood vessels and finally needs to be targeted at the cancer site by crossing or travelling the endothelial barrier. Size, shape, charge and density of nanoparticles are the important parameters which decide the trajectory, dynamic, stability and distribution while circulation in blood stream and subsequent mechanism of infiltration in tumor tissues and cells. To reach the tumor site and to successfully deliver the therapeutic drug, vascular barrier needs to be crossed.

NPs usually follow two different strategies i.e. passive route and active route to target cancer site. Majority of the nanomedicine assumes and follow the passive phenomenon known as enhanced permeability and retention (EPR) route which is totally dependent on the tumor type and stage of cancer. In EPR effect, NPs passively cross leaky vessels of tumor tissues and accumulate into the cancer cells. Degree of leakiness depends on the tumor location, vasculature and progression stage [159]. Nano-carriers once injected for the systemic delivery of cancer therapeutics; in the circulation they are coated with plasma proteins and readily available to clearance by mononuclear phagocyte system (MPS). NPs avoid MPS by PEG surface coating and this NP extraverted from tumor blood vessels into tumor by margination (ability to flow towards blood vessels walls) leading to longer half-life through prolonged circulation in blood [160]. Inside tumor cell, NPs release their cargo by the process of particle erosion and diffusion. Non-spherical particles $(100 \mathrm{~nm})$ marginate more rapidly and extravert through the leaky tumor vasculature and penetrate into 
tumor mass. Surface modification involving zwitterionic ligands eg. cysteine and glutathione or PEGylation facilitate escape of NPs from reticuloendothelial system (RES) and finally reach the target tumor tissue [161]. Even poor lymphatic drainage system provides permeability to cross the barrier and allow NP to passively diffuse/penetrate to the target the cancer site. So, EPR effect is mostly seen in mature tumor and attributed by the nutrient-starved condition in tumor.

Contrary to above passive route, greater selectivity and specificity for cancer cells is achieved surface modification of NPs with ligands like transferrin, folic acid and antibodies for specific targeted therapy on glycan surface of the tumor cells [162]. Transcellular route and movement between the endothelial cells are the newer strategies. Receptor mediated internalization is facilitated by the endothelial cells (ECs) surface receptors following transcellular transport across the EC barrier is accompanied with certain shortcoming like lysosomal digestion in EC cellular processing and few EC specific markers. Therefore, more profound mode is paracellular route having VE-cadherins and occludins junctions across the narrow intercellular spaces between two endothelial cells (EC). This gap between the ECs is the new target and needs to be widening by NP to access the tumor site. So, for, targeting early and benign cancer, nanomaterial induced endothelial leakiness (NanoEL) phenomenon is emerging. NPs are now designed to induce endothelial leakiness forming capillary beds without EPR effect. Physiochemical intrinsic properties of NPs like charge and density regulates the NanoEL and cancer progression. Gold NPs $(10-30 \mathrm{~nm})$ is recently exploited as NanoEL inducing particles in human mammary endothelial cells [163]. Using charge as an important entity, AuNPs charge (negatively and positively charged NPs) could be tuned for NanoEL effect. Negatively charged gold NPs (-AuNPs) could be attracted and bound towards positively charged cell-cell junction and could induce NP driven leaky effect to access the tumor. Using the same concept, positively charged AuNPs (+AuNPs) are attracted by glycocalyx and modulate the degree of NanoEL effect by endocytosis (paracellular route) into the endothelial cells (EC) barrier. However, based on bouncing particle hypothesis negatively charged NP (-AuNPs) caused more NanoEL effect (Fig. 4, [164]).

Micron sized gaps between endothelial cells could be easily passed by NPs but not the nanosized gaps between microvascular capillary. Therefore, size of nanoparticle is another important feature, as smaller sized NPs can easily penetrate and accumulate in the leaky tumor vessels. Even density of the NPs dictates the NanoEL effect. Using SiNPs library of varying densities, Tay et al, [165] reported high endothelial permeability with particle density between $1.57 \mathrm{~g} / \mathrm{cm} 3$ to $1.72 \mathrm{~g} / \mathrm{cm} 3$. Same group of researchers tried various small sized (15-25nm) NPs like titanium dioxide $\left(\mathrm{TiO}_{2}\right)$, silica dioxide $\left(\mathrm{SiO}_{2}\right)$ and silver $(\mathrm{Ag})$ for NanoEL effect. These NPs randomly entered nanometer wide gaps of the adherens junctions between endothelial cells disrupt the VE-Cad-VE-Cad interactions and produce micron sized gaps between endothelial cells. Setyawati et al., [166] also demonstrated a novel non-receptor mediated endothelial cell leakiness (ECL) by $\mathrm{TiO}_{2}$ NPs targeting specific interaction with VE-cadherin protein. $\mathrm{TiO}_{2}$ NPs migrate into the interendothelial adherents junction niche and binds directly to VE-cadherin resulting in cascade of intracellular reactions and finally disruptcell-cell interactions. This facilitates application of the nanomedicine for the treatment of cancer. Surface re-modelling of the NPs like addition of chemical groups on the surface of Nanodiamonds also known to modulate the degree of leakiness in the vascular barrier. Such modified nanodiamonds widen the paracellular route opening of EC barrier by increasing the intracellular $\mathrm{Ca}^{2+}$ and ROS, inducing the cytoskeleton remodelling resulting in vasculature leakiness [167]. This demonstrated the possibility for doxorubicin to penetrate effectively through leaked vascular barrier to reach the cancer cells with high efficacy of drug delivery.

NanoEL effect although is beneficial in enhancing the delivery of drug carrying NP, but it's no specificity to induce spontaneous leakiness in other blood vessels could have adverse effects. Studies by Setyawati et al.,[163] also showed side-effects of $\mathrm{TiO}_{2}$ NanoEL induced leakiness of subcutaneous blood vessels in mice and enhanced circulating melanoma metastasis to lungs in the mouse model. These inherited side-effects of NPs induced non-specific NanoEL effect and high probability of interaction with biological tissues has raised safety concerns which need to be addressed. Designing of specific and smart NanoEL driven nanoparticles can be the future of cancer nanomedicine which could target the wide spectrum of tumor including TNBC.

\section{Novel research for cancer detection and treatment: In news}

Scientists from University of Queensland developed a method to detect cancer in 10 min using blood sample with accuracy of $90 \%$. They developed such sensitive detection test using simple colour changing fluid to reveal the presence of malignant cells based on the hypothesis that normal DNA and Cancer DNA shows different adherence to metal surfaces and stick differently [168]. In addition, researcher from Rosalind Institute developed a revolutionary high-speed camera that can take 100 million photos per sec at 1-megapixel resolution across the spectrum from Infra-red (IF) to ultra-violet (UV). This high-speed camera helps the researchers to see how a drug reacts with a cancer tumor at a microscopic level 


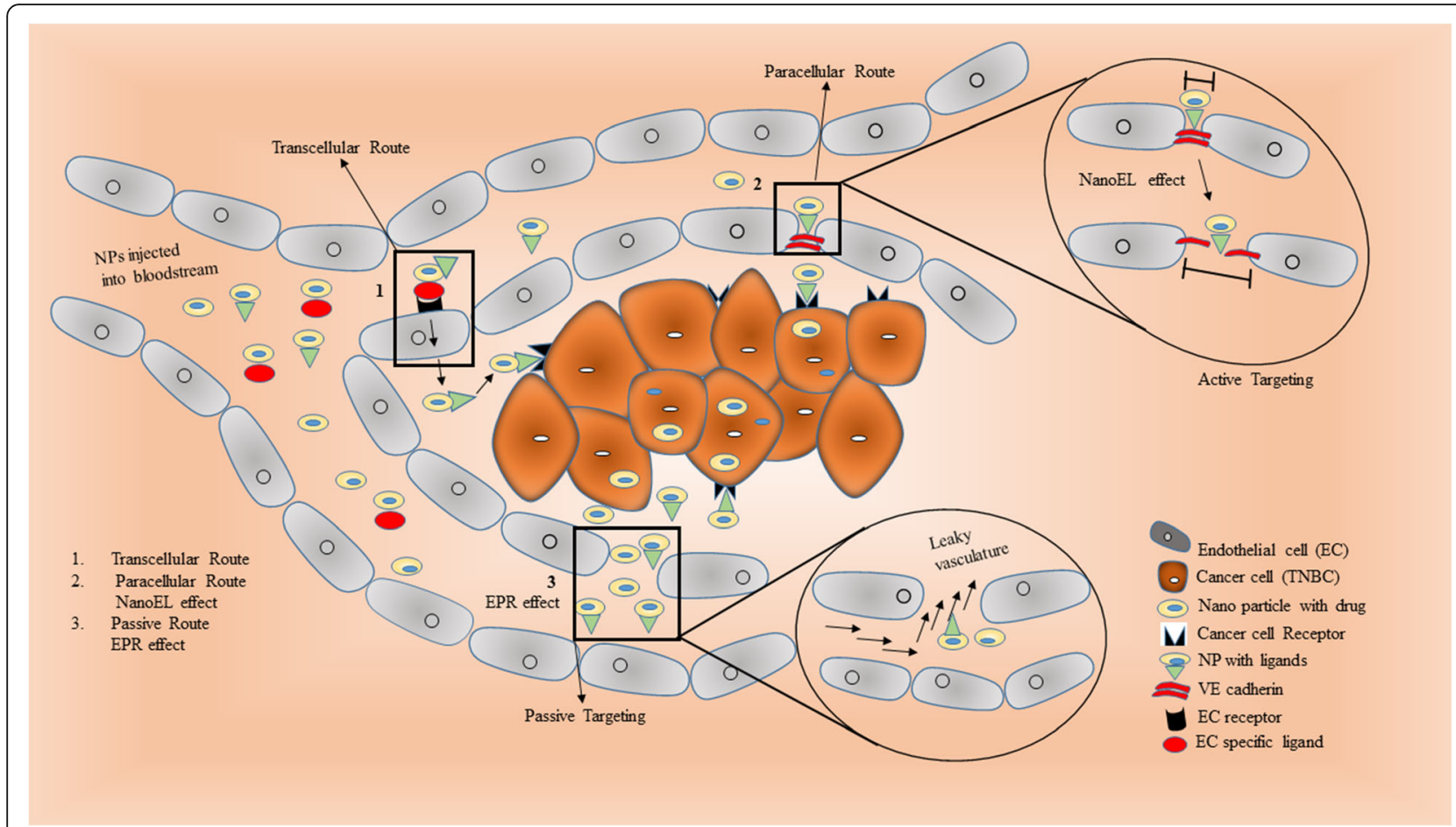

Fig. 4 Schematic representation of different routes followed by nanoparticles in cancer therapy. (1) In transcellular route, the drug carrying nanoparticle injected into the bloodstream passes through the endothelial cell and reaches as the cancer site. (2) Whereas in paracellular route, the nanoparticle passes through the inter-endothelial cell spaces and known as active targeting. These nanoparticles induce leakiness by widening the gap between the endothelial cells and enhance the cancer cell targeting also known as naoEL effect. (3) Passive targeting is the classical and common phenomenon where the nanoparticle transverse through the leaky vasculature by EPR effect to the site of cancer cells.

in Real-Time [169]. Recently, Israeli scientists claim to develop $100 \%$ cancer cure by early 2020 , using a treatment known as MuTaTo which stands for Multi-TargetToxin [170]. This treatment is developed by Accelerated Evolution Biotechnologies Ltd (AEBi) based on the SoAP Technology. Successful preliminary trials on mice using a combination of cancer targeting peptide and MuTaTo toxin, showing the specificity towards cancer cells and terminate cancer cells without harming normal healthy cells and tissues. The concept that makes MuTaTo treatment different from existing treatments is the attacking cancer cells receptors from 3 different directions simultaneously at the same time and reflect the scope of hyper-personalized treatment to each patient in the long run. Recently the researchers from the University of Queensland and Albert Einstein College of Medicine jointly developed a statistical approach known as Oncomix [171] to examine breast cancer data from The Cancer Genome Atlas patient database and identified the most promising target known as Chromobox 2 (CBX2) which has been shown to have high levels in aggressive sub-type of breast cancerand therefore could be a potential breast cancer treatment target. Oncomix, captures transcriptional heterogeneity in tumor and identifies oncogene candidates that were over expressed in a subset of breast tumors. Intronic DNA methylation was strongly associated with the over expression of Chromobox 2 (CBX2), an oncogene. CBX2 over expression in breast tumors was associated with the up regulation of genes involved in cell cycle progression and with poor 5-year survival [171]. This discovery highlights the potential value of the Oncomix approach and will open new therapeutic avenues and move us closer to personalized medicine.

\section{Artificial intelligence (Al): Advanced cancer diagnosis and treatment (Futuristic approach)}

Artificial intelligence revolutionizes every bit of science whether it is engineering, robots, defence, nanotechnology or medical science. Everything is now going smart whether it is our phones or watches, thanks to artificial intelligence. Recently, Cancer Research UK Imperial centre, DeepMind Health, AI health research team at Google and UK funded OPTIMAM mammography database at the Royal surrey country hospital NHS foundation trust collaborated to improve breast cancer diagnosis using AI [172]. Machine learning technology from DeepMind Health and de-identified mammograms, possibly train computer algorithm to analyse these images more accurately, leading to earlier detection and 
therapeutic intervention for patients (Fig. 5). However, AI in medical imaging is still in its infancy, but such collaborations will soon develop cutting-edge machine learning to detect and diagnose breast cancer more selectively and accurately. Scientists at Imperial College London and the University of Melbourne developed machine learning software known as Radiomics Prognostic Vector (RPV) that can predict the prognosis of 364 ovarian cancer patients four times as accurate at predicting outcomes when compared to conventional methods in an initial trial by examining four biological features of tumor including structure, shape, size and genetic makeup in CT scans [173].

\section{Al guided nano-robots for cancer treatment: Hypothetical view}

Artificial intelligence (AI) guided nano-robot or selflearned/evolved, made of biocompatible/ degradable material (carragennin/capsule coat) which can carry drug specifically to the target cancer site must have all ancillary like sensor for the target, tracking sensor, self-detonation property to get rid of from the body after serving the required purpose. In near future, nano-medicine research will be powered by AI, not only to diagnose and treat cancer, but to deal with all other disease. Even though much success is achieved with the nanotechnology in cancer research and treatment, the intervention of artificial intelligence in nanotechnology could be the promising solution.

\section{Conclusions}

Triple-negative breast cancer still consider as an aggressive subtype of breast cancer. The high heterogeneous nature accompanied with low survival rate continues as a challenge to the oncologist. Currently available therapies are inadequate and needs to be supplemented with novel targeted therapies to tackle the tenacious TNBC tumor. With the emergence of nanoscience, nanomedicine is likewise advancing in terms of accurate and rapid diagnosis and target directed remedy in cancers.

Nanoparticles are the key players in most cancers research due to its target specific multifunctional properties. These nano-missiles are well equipped with arsenals to execute their role in destroying the most cancer cells. The possibility to load/encapsulate drug, not only protect drug but additionally increase biological half-life of anti-cancerous drug which eventually lower the overall dose of drug administration. Such encapsulation aids the slow and concentrated release of drug at cancer site due to enhanced permeability and retention (EPR) thereby reducing the side-effects to other non-cancerous healthy cells. The selected targeted delivery of drug increases

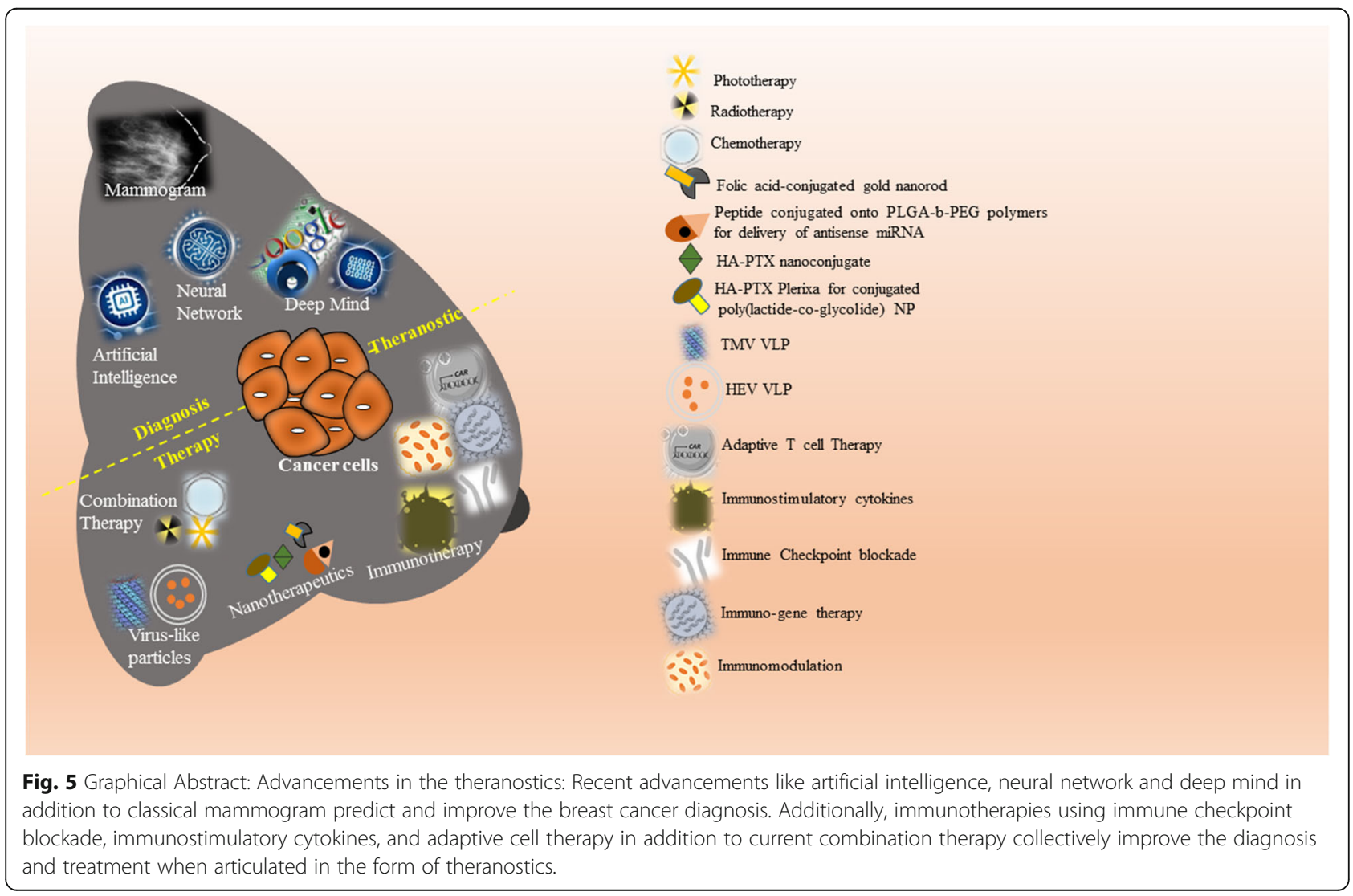


treatment efficacy. Versatility in terms of size, materials used, fabrication technologies, in addition to biocompatibility and biodegradability certified these nanocarriers for cancer diagnostics and therapeutics. Successful designing of dual-functionality nanoparticles for simultaneously monitoring (imaging) and treating (drug) of cancer: theranostic had been developed with a very promising future in cancer. High multiplexibility by conjugating ligands to nanoparticles facilitates the combined targeted delivery of drug at precise site to selectively destroy tumor cells.

Demonstrating the diverse application, still there are few challenges which are needing to be addressed. Majority of the nanovehicles in TNBC trials are designed either for targeted diagnosis or targeted therapy. A very few studies demonstrating the utility of these nanovehicles are conducted in in-vitro TNBC cell line and in in-vivo xenograft mouse models. Limited TNBC (cell or animal) model simulating the actual clinical situation is still a challenge and to be addressed promising immunotherapy with the recently approved drug and in-trials drugs surely will limit the cancer progression and advance the treatment. Even the better understanding of how the nanoparticles enhance and mediate the immune response also improvises the TNBC treatment. Expertise in integrating various modalities in one system and understanding the molecular and cellular interaction is still a limitation which needs a promising solution. Success of few drugs for breast cancer also showing promising results with TNBC cell culture models, these endeavours successfully motivates the concept of drug-repurposing for TNBC treatment. Finally, nanotechnology-based drug delivery with enough ancillary (drugs, ligand, and probe) system can improve diagnostic ability and therapeutic outcomes, thereby contributing to enhanced patient survival and well-being.

\footnotetext{
Abbreviations

ACT: Adaptive cell transfer-based therapy; Al: Artificial Intelligence; AODNs: Antisenseoligodeoxynucleotides; BC: Breast cancer; CAR: Chimeric antigen receptor; CIK: Cytokine-induced killer; CTLs: Cytotoxic T Iymphocytes; EPR: Enhanced permeation and retention; ER: Estrogen receptor; FDA: Food and Drug Administration; GFP: Green fluorescent protein; HCC: Human Hepatocellular carcinoma; HDAC: Histone deacetylase; HER-2: Human epidermal growth factor receptor-2; IHC: Immunohistochemistry; LAG3: Lymphocyte activating gene; LAK: Lymphokine-activated killer cells; MAGE: Melanoma associated antigen-3; MAK: Macrophages activated killer; MPS: Mononuclear phagocyte system; MRI: Magnetic resonance imaging; NanoEL: Nanoparticles induced endothelial leakiness; NIR: Near Infra-red; NSCLC: Non-small cell lung carcinoma; o-MWNTs: Oxidized multi-walled carbon nanotubes; PARP: Poly (ADP-ribose) polymerase; PD-1: Programmed death 1; PD-L1: Programmed death ligand-1; PEG: Polyethylene glycol; pHLIP: pH low insertion peptide; PR: Progesterone receptor; PRINT: Particle replication in nonwetting templates; PTX: Paclitaxel; RES: Reticuloendothelial system; ROS: Reactive oxygen species; RT: Radiation treatment; RTK: Receptor tyrosine kinase; TAA: Tumor associated antigen; TCM: Terahertz $(\mathrm{THz})$ chemical microscopy; TK: Tyrosine kinase; TLS: Tumor lysis syndrome; TME: Tumor microenvironment; TMT: Tumor metastasis targeting; TNBC: Triple-negative breast cancer; TSA: Tumor specific antigen; UPAR: Urokinase plasminogen activator receptor; VCAM-1: Vascular cell
}

adhesion molecule-1; VEGF: Vascular endothelial growth factor; VLP: Virus like particles

\section{Acknowledgements \\ Not applicable}

\section{Authors' contributions}

$\mathrm{VT}$ drafted the manuscript and prepared the figures and tables. RVK designed the review and revised the manuscript. Both the authors approved the submitted version of the manuscript.

\section{Funding}

This work was financially supported by a Research Grant (Project No. RDU150379 and RDU1803181) from University Malaysia Pahang (www.ump. edu.my) and Fundamental Research Grant Scheme (FRGS/1/2017/TK05/ UMP//1, RDU170130) from Ministry of Higher Education (MoHE), Malaysia for which the authors are very grateful.

\section{Availability of data and materials}

Not applicable

Ethics approval and consent to participate

Not Applicable

\section{Consent for publication}

Not applicable

\section{Competing interests}

The authors declare that they have no competing interests

\section{Author details}

${ }^{1}$ Department of Virology, Postgraduate Institute of Medical Education and Research, PGIMER, Chandigarh 160012, India. ${ }^{2}$ Faculty of Chemical and Process Engineering Technology, College of Engineering

Technology,University Malaysia Pahang, Tun Razak Highway, 26300 Kuantan, Pahang, Malaysia. ${ }^{3}$ Center of Excellence for Advanced Research in Fluid Flow, University Malaysia Pahang, 26300, Kuantan, Pahang, Malaysia.

Received: 18 July 2019 Accepted: 10 October 2019

Published online: 28 October 2019

\section{References}

1. EER Preliminary Cancer Incidence Rate Estimates for 2017, and diagnosis years 2000 to 2017, SEER 18, National Cancer Institute. Bethesda, MD, https://seer.cancer.gov/statistics/preliminary-estimates/, based on the February 2019 SEER data submission and the November 2018 SEER data submission. Posted to the SEER web site, September 2019.

2. Siegel RL, Miller KD, Jemal A. Cancer statistics, 2017. CA Cancer J Clin. 2017; 67(1):7-30. https://doi.org/10.3322/caac.21387.

3. He J, Yang J, Chen W, Wu H, Yuan Z, Wang K, et al. Molecular Features of Triple Negative Breast Cancer: Microarray Evidence and Further Integrated Analysis. Sossey-Alaoui K, editor. PLoS One. 2015;10(6):e0129842. https://doi. org/10.1371/journal.pone.0129842.

4. He Y, Jiang Z, Chen C, Wang X. Classification of triple-negative breast cancers based on Immunogenomic profiling. J Exp Clin Cancer Res. 2018; 37(1):327 http://www.ncbi.nlm.nih.gov/pubmed/30594216.

5. Bonsang-Kitzis H, Sadacca B, Hamy-Petit AS, Moarii M, Pinheiro A, Laurent C, et al. Biological network-driven gene selection identifies a stromal immune module as a key determinant of triple-negative breast carcinoma prognosis. Oncoimmunology. 2016;5(1):e1061176. https://doi.org/10.1080/2162402X. 2015.1061176.

6. Burstein MD, Tsimelzon A, Poage GM, Covington KR, Contreras A, Fuqua SAW, et al. Comprehensive genomic analysis identifies novel subtypes and targets of triple-negative breast cancer. Clin Cancer Res. 2015;21(7):1688-98. https://doi.org/10.1158/1078-0432.CCR-14-0432.

7. Gangi A, Chung A, Mirocha J, Liou DZ, Leong T, Giuliano AE. Breastconserving therapy for triple-negative breast cancer. JAMA Surg. 2014; 149(3):252-8. https://doi.org/10.1001/jamasurg.2013.3037.

8. Foulkes WD, Smith IER-FJ. No Title. N Engl J Med. 2010;363:1938-48. 
9. Dai X, Li T, Bai Z, Yang Y, Liu X, Zhan J, et al. Breast cancer intrinsic subtype classification, clinical use and future trends. Am J Cancer Res. 2015;5(10): 2929-43 http://www.ncbi.nlm.nih.gov/pubmed/26693050.

10. Lord CJ, Ashworth A. BRCAness revisited. Nat Rev Cancer. 2016;16(2):110-20 http://www.nature.com/articles/nrc.2015.21.

11. Engebraaten O, Vollan HKM, Børresen-Dale A-L. Triple-negative breast cancer and the need for new therapeutic targets. Am J Pathol. 2013;183(4): 1064-74 https://linkinghub.elsevier.com/retrieve/pii/S0002944013004616.

12. Kutty RV, Feng S-S. Cetuximab conjugated vitamin E TPGS micelles for targeted delivery of docetaxel for treatment of triple negative breast cancers. Biomaterials. 2013;34(38):10160-71:https://inkinghub.elsevier.com/ retrieve/pii/S0142961213011265.

13. Svenson AT. Adv Drug Deliv Rev. 2012;64:102-15.

14. Khodabandehloo H, Zahednasab H, Ashrafi Hafez A. Nanocarriers Usage for Drug Delivery in Cancer Therapy. Iran J Cancer Prev. 2016; In Press (In Press): e3966. http://www.ncbinlm.nih.gov/pubmed/27482328

15. Kumari P, Ghosh B, Biswas S. Nanocarriers for cancer-targeted drug delivery. J Drug Target. 2016;24(3):179-91. https://doi.org/10.3109/1061186X.2015.1051049.

16. Setyawati MI, Kutty RV, Leong DT. DNA Nanostructures Carrying Stoichiometrically Definable Antibodies. Small. 2016;12(40):5601-11. https:// doi.org/10.1002/smll.201601669.

17. $\mathrm{Mu} \mathrm{Q}$, Wang $\mathrm{H}$, Zhang $\mathrm{M}$. Nanoparticles for imaging and treatment of metastatic breast cancer. Expert Opin Drug Deliv. 2017;14(1):123-36. https:// doi.org/10.1080/17425247.2016.1208650

18. Schmid P, Adams S, Rugo HS, Schneeweiss A, Barrios $\mathrm{CH}$, Iwata $\mathrm{H}$, et al. Atezolizumab and Nab-Paclitaxel in Advanced Triple-Negative Breast Cancer. N Engl J Med. 2018;379(22):2108-21. https://doi.org/10.1056/ NEJMoa1809615.

19. Del Paggio JC. Immunotherapy: Cancer immunotherapy and the value of cure. Nat Rev Clin Oncol. 2018;15(5):268-70. https://doi.org/10.1038/ nrclinonc.2018.27.

20. Schmadeka R, Harmon BE, Singh M. Triple-Negative Breast Carcinoma. Am J Clin Pathol. 2014;141(4):462-77 https://academic.oup.com/ajcp/ article/141/4/462/1760538.

21. Herranz M, Ruibal A. Optical imaging in breast cancer diagnosis: the next evolution. J Oncol. 2012;2012:863747 http://www.hindawi.com/journals/jo/2 012/863747/.

22. Dogan BE, Turnbull LW. Imaging of triple-negative breast cancer. Ann Oncol Off J Eur Soc Med Oncol. 2012;23(suppl 6):vi23-9. https://doi.org/10.1093/ annonc/mds191.

23. Kreike $B$, van Kouwenhove $M$, Horlings $H$, Weigelt $B$, Peterse $H$, Bartelink $H$, et al. Gene expression profiling and histopathological characterization of triple-negative/basal-like breast carcinomas. Breast Cancer Res. 2007;9(5):R65. https://doi.org/10.1186/bcr1771.

24. Kyndi M, Sørensen FB, Knudsen H, Overgaard M, Nielsen HM, Overgaard J, et al. Estrogen receptor, progesterone receptor, HER-2, and response to postmastectomy radiotherapy in high-risk breast cancer: the Danish Breast Cancer Cooperative Group. J Clin Oncol. 2008;26(9):1419-26. https://doi.org/ 10.1200/JCO.2007.14.5565.

25. Bayraktar S, Glück S. Molecularly targeted therapies for metastatic triplenegative breast cancer. Breast Cancer Res Treat. 2013;138(1):21-35. https:// doi.org/10.1007/s10549-013-2421-5.

26. Shi Y, Jin J, Ji W, Guan X. Therapeutic landscape in mutational triple negative breast cancer. Mol Cancer. 2018;17(1):99 http://www.ncbi.nlm.nih. gov/pubmed/30007403.

27. Setyawati MI, Kutty RV, Tay CY, Yuan X, Xie J, Leong DT. Novel theranostic DNA nanoscaffolds for the simultaneous detection and killing of Escherichia coli and Staphylococcus aureus. ACS Appl Mater Interfaces. 2014;6(24): 21822-31. https://doi.org/10.1021/am502591c.

28. Dai W, Yang F, Ma L, Fan Y, He B, He Q, et al. Combined mTOR inhibitor rapamycin and doxorubicin-loaded cyclic octapeptide modified liposomes for targeting integrin a3 in triple-negative breast cancer. Biomaterials. 2014;35(20): 5347-58 https:/linkinghub.elsevier.com/retrieve/pii/S014296121400283X.

29. Lee S-M, Ahn RW, Chen F, Fought AJ, O'Halloran TV, Cryns VL, et al. Biological evaluation of $\mathrm{pH}$-responsive polymer-caged nanobins for breast cancer therapy. ACS Nano. 2010;4(9):4971-8. https://doi.org/10. 1021/nn100560p.

30. Matsumura Y, Hamaguchi T, Ura T, Muro K, Yamada Y, Shimada Y, et al. Phase I clinical trial and pharmacokinetic evaluation of NK911, a micelleencapsulated doxorubicin. Br J Cancer. 2004;91(10):1775-81 http://www. nature.com/articles/6602204.
31. Sun Y, Zou W, Bian S, Huang Y, Tan Y, Liang J, et al. Bioreducible PAA-g-PEG graft micelles with high doxorubicin loading for targeted antitumor effect against mouse breast carcinoma. Biomaterials. 2013;34(28):6818-28 https:// linkinghub.elsevier.com/retrieve/pii/S014296121300608X.

32. Zhang $H$, Hu H, Zhang $H$, Dai W, Wang $X$, Wang $X$, et al. Effects of PEGylated paclitaxel nanocrystals on breast cancer and its lung metastasis. Nanoscale. 2015;7(24):10790-800 http://xlink.rsc.org/?DOl=C4NR07450E.

33. Andey T, Sudhakar G, Marepally S, Patel A, Banerjee R, Singh M. Lipid nanocarriers of a lipid-conjugated estrogenic derivative inhibit tumor growth and enhance cisplatin activity against triple-negative breast cancer: pharmacokinetic and efficacy evaluation. Mol Pharm. 2015;12(4):1105-20. https://doi.org/10.1021/mp5008629.

34. Awada A, Bondarenko IN, Bonneterre J, Nowara E, Ferrero JM, Bakshi AV, et al. A randomized controlled phase II trial of a novel composition of paclitaxel embedded into neutral and cationic lipids targeting tumor endothelial cells in advanced triple-negative breast cancer (TNBC). Ann Oncol Off J Eur Soc Med Oncol. 2014;25(4):824-31. https://doi.org/10.1093/ annonc/mdu025.

35. Sharma A, Jain N, Sareen R. Nanocarriers for diagnosis and targeting of breast cancer. Biomed Res Int. 2013;2013:960821 http://www.hindawi.com/ journals/bmri/2013/960821/.

36. Taurin S, Nehoff H, Diong J, Larsen L, Rosengren RJ, Greish K. Curcuminderivative nanomicelles for the treatment of triple negative breast cancer. J Drug Target. 2013;21 (7):675-83. https:/doi.org/10.3109/1061186X.2013.796955.

37. Muthu MS, Kutty RV, Luo Z, Xie J, Feng S-S. Theranostic vitamin E TPGS micelles of transferrin conjugation for targeted co-delivery of docetaxel and ultra bright gold nanoclusters. Biomaterials. 2015;39:234-48 https:// linkinghub.elsevier.com/retrieve/pii/S0142961214011648.

38. Matsumura Y. Preclinical and clinical studies of NK012, an SN-38incorporating polymeric micelles, which is designed based on EPR effect. Adv Drug Deliv Rev. 2011;63(3):184-92 https://linkinghub.elsevier.com/ retrieve/pii/S0169409X10001353.

39. Bawarkki WE, Chidlowsky E, Bharali DJ, Mousa SA. Emerging nanopharmaceuticals. Nanomedicine. 2008;4(4):273-82 https://linkinghub. elsevier.com/retrieve/pii/S1549963408000841.

40. Wang $P$, Zhao X-H, Wang Z-Y, Meng M, Li X, Ning Q. Generation 4 polyamidoamine dendrimers is a novel candidate of nano-carrier for gene delivery agents in breast cancer treatment. Cancer Lett. 2010;298(1):34-49 https://inkinghub.elsevier.com/retrieve/pii/S0304383510003137.

41. Finlay J, Roberts CM, Lowe G, Loeza J, Rossi JJ, Glackin CA. RNA-based TWIST1 inhibition via dendrimer complex to reduce breast cancer cell metastasis. Biomed Res Int. 2015;2015:382745 http://www.hindawi.com/ journals/bmri/2015/382745/.

42. Zhang L, Varma NR, Gang ZZ, Ewing JR, Arnab AS. J Nanomed Nanotechnol. 2016;7:404.

43. Elsabahy M, Wooley KL. Design of polymeric nanoparticles for biomedical delivery applications. Chem Soc Rev. 2012;41(7):2545-61 http//xlink.rsc.org/?DOl=c2cs15327k.

44. Xu J, Luft JC, Yi X, Tian S, Owens G, Wang J, et al. RNA Replicon Delivery via Lipid-Complexed PRINT Protein Particles. Mol Pharm. 2013;10(9):3366-74. https://doi.org/10.1021/mp400190z.

45. Johnstone TC, Kulak N, Pridgen EM, Farokhzad OC, Langer R, Lippard SJ Nanoparticle encapsulation of mitaplatin and the effect thereof on in vivo properties. ACS Nano. 2013;7(7):5675-83. https://doi.org/10.1021/ nn401905g.

46. Passarella RJ, Spratt DE, van der Ende AE, Phillips JG, Wu H, Sathiyakumar V, et al. Targeted Nanoparticles That Deliver a Sustained, Specific Release of Paclitaxel to Irradiated Tumors. Cancer Res. 2010;70(11):4550-9. https://doi. org/10.1158/0008-5472.CAN-10-0339.

47. Cardillo TM, Govindan SV, Sharkey RM, Trisal P, Arrojo R, Liu D, et al. Sacituzumab Govitecan (IMMU-132), an Anti-Trop-2/SN-38 Antibody-Drug Conjugate: Characterization and Efficacy in Pancreatic, Gastric, and Other Cancers. Bioconjug Chem. 2015;26(5):919-31. https://doi.org/10.1021/acs.bioconjchem.5b00223.

48. Cao H, Zhang Z, Zhao S, He X, Yu H, Yin Q, et al. Hydrophobic interaction mediating self-assembled nanoparticles of succinobucol suppress lung metastasis of breast cancer by inhibition of VCAM- 1 expression. J Control Release. 2015;205:162-71 https://linkinghub.elsevier. com/retrieve/pii/S016836591500036X.

49. Devulapally R, Sekar NM, Sekar TV, Foygel K, Massoud TF, Willmann JK, et al. Polymer nanoparticles mediated codelivery of antimiR-10b and antimiR-21 for achieving triple negative breast cancer therapy. ACS Nano. 2015;9(3): 2290-302. https://doi.org/10.1021/nn507465d. 
50. Deng ZJ, Morton SW, Ben-Akiva E, Dreaden EC, Shopsowitz KE, Hammond PT. Layer-by-Layer Nanoparticles for Systemic Codelivery of an Anticancer Drug and siRNA for Potential Triple-Negative Breast Cancer Treatment. ACS Nano. 2013;7(11):9571-84. https://doi.org/10.1021/nn4047925.

51. Shan D, Li J, Cai P, Prasad P, Liu F, Rauth AM, et al. RGD-conjugated solid lipid nanoparticles inhibit adhesion and invasion of av $\beta 3$ integrinoverexpressing breast cancer cells. Drug Deliv Transl Res. 2015;5(1):15-26. https://doi.org/10.1007/s13346-014-0210-2.

52. Zhang T, Prasad P, Cai P, He C, Shan D, Rauth AM, et al. Dual-targeted hybrid nanoparticles of synergistic drugs for treating lung metastases of triple negative breast cancer in mice. Acta Pharmacol Sin. 2017;38(6):835-47. https://doi.org/10.1038/aps.2016.166.

53. Su X-Y, Liu P-D, Wu H, Gu N. Enhancement of radiosensitization by metalbased nanoparticles in cancer radiation therapy. Cancer Biol Med. 2014; 11(2):86-91 http://www.ncbi.nlm.nih.gov/pubmed/25009750.

54. Kong T, Zeng J, Wang X, Yang X, Yang J, McQuarrie S, et al. Enhancement of radiation cytotoxicity in breast-cancer cells by localized attachment of gold nanoparticles. Small. 2008;4(9):1537-43. https://doi.org/10.1002/smll. 200700794.

55. Liu P, Huang Z, Chen Z, Xu R, Wu H, Zang F, et al. Silver nanoparticles: a novel radiation sensitizer for glioma? Nanoscale. 2013;5(23):11829-36 http:// xlink.rsc.org/?DOI=c3nr01351k.

56. Wahab R, Siddiqui MA, Saquib Q, Dwivedi S, Ahmad J, Musarrat J, et al. ZnO nanoparticles induced oxidative stress and apoptosis in HepG2 and MCF-7 cancer cells and their antibacterial activity. Colloids Surf B Biointerfaces. 2014; 117:267-76 https://linkinghub.elsevier.com/retrieve/pii/S0927776514001052.

57. Baskar G, Chandhuru J, Sheraz Fahad K, Praveen AS, Chamundeeswari M, Muthukumar T. Anticancer activity of fungal L-asparaginase conjugated with zinc oxide nanoparticles. J Mater Sci Mater Med. 2015;26(1):5380. https://doi. org/10.1007/s10856-015-5380-z

58. Hackenberg S, Scherzed A, Harnisch W, Froelich K, Ginzkey C, Koehler C, et al. Antitumor activity of photo-stimulated zinc oxide nanoparticles combined with paclitaxel or cisplatin in HNSCC cell lines. J Photochem Photobiol B. 2012;114:87-93 https://linkinghub.elsevier.com/retrieve/pii/S1 011134412001091.

59. Wang $Y$, Yang F, Zhang $H X$, Zi XY, Pan XH, Chen F, et al. Cuprous oxide nanoparticles inhibit the growth and metastasis of melanoma by targeting mitochondria. Cell Death Dis. 2013;4(8):e783 http://www.nature.com/ articles/cddis2013314.

60. Zhou M, Zhao J, Tian M, Song S. Nanoscale. 2015;46:19438-47.

61. Pešić M, Podolski-Renić A, Stojković S, Matović B, Zmejkoski D, Kojić V, et al. Anti-cancer effects of cerium oxide nanoparticles and its intracellular redox activity. Chem Biol Interact. 2015;232:85-93 https://inkinghub.elsevier.com/ retrieve/pii/S000927971500112X.

62. Huang HS, Hainfeld JF. Intravenous magnetic nanoparticle cancer hyperthermia. Int J Nanomedicine. 2013;8:2521-32 http://www.dovepress. com/intravenous-magnetic-nanoparticle-cancer-hyperthermia-peerreviewed-article-IJN.

63. Kossatz S, Grandke J, Couleaud P, Latorre A. Breast Cancer Res. 2015;17:66.

64. Pourtau L, Oliveira H, Thevenot J, Wan Y, Brisson AR, Sandre O, et al. Antibody-functionalized magnetic polymersomes: in vivo targeting and imaging of bone metastases using high resolution MRI. Adv Healthc Mater. 2013;2(11):1420-4. https://doi.org/10.1002/adhm.201300061.

65. Kievit FM, Stephen ZR, Veiseh O, Arami H, Wang T, Lai VP, et al. Targeting of primary breast cancers and metastases in a transgenic mouse model using rationally designed multifunctional SPIONs. ACS Nano. 2012;6(3):2591-601. https://doi.org/10.1021/nn205070h.

66. Yang M, Meng J, Cheng X, Lei J, Guo H, Zhang W, et al. Multiwalled carbon nanotubes interact with macrophages and influence tumor progression and metastasis. Theranostics. 2012;2(3):258-70 http://www. thno.org/v02p0258.htm.

67. Burke AR, Singh RN, Carroll DL, Wood JCS, D'Agostino RB, Ajayan PM, et al. The resistance of breast cancer stem cells to conventional hyperthermia and their sensitivity to nanoparticle-mediated photothermal therapy. Biomaterials. 2012;33(10):2961-70 https://linkinghub.elsevier.com/retrieve/ pii/S0142961211015353.

68. Chow EK, Zhang X-Q, Chen M, Lam R, Robinson E, Huang H, et al. Nanodiamond therapeutic delivery agents mediate enhanced chemoresistant tumor treatment. Sci Transl Med. 2011;3(73):73ra21 http:// stm.sciencemag.org/cgi/doi/10.1126/scitranslmed.3001713.

69. Xiao JS, Duan XP, Yin Q, Zhang ZY. Biomaterials. 2013;34:9648-56.
70. Li X, Zhang W, Liu L, Zhu Z, Ouyang G, An Y, et al. In vitro selection of DNA aptamers for metastatic breast cancer cell recognition and tissue imaging. Anal Chem. 2014;86(13):6596-603. https://doi.org/10.1021/ac501205q.

71. Huang YF, Lin YW, CH LZH. J nanopart Res. 2009;11:775-83.

72. Hassan EM. Sensors Actuators B Chem; 2019.

73. Tang L, Yang X, Dobrucki LW, Chaudhury I, Yin Q, Yao C, et al. Aptamerfunctionalized, ultra-small, monodisperse silica nanoconjugates for targeted dual-modal imaging of lymph nodes with metastatic tumors. Angew Chem Int Ed Engl. 2012;51(51):12721-6. https://doi.org/10.1002/anie.201205271.

74. Shi S, Hong H, Orbay H, Graves SA, Yang Y, Ohman JD, et al. ImmunoPET of tissue factor expression in triple-negative breast cancer with a radiolabeled antibody Fab fragment. Eur J Nucl Med Mol Imaging. 2015;42(8):1295-303. https://doi.org/10.1007/s00259-015-3038-1.

75. LeBeau AM, Sevillano N, King ML, Duriseti S, Murphy ST, Craik CS, et al. Imaging the Urokinase Plasminongen Activator Receptor in Preclinical Breast Cancer Models of Acquired Drug Resistance. Theranostics. 2014;4(3): 267-79 http://www.thno.org/v04p0267.htm

76. Rousseau C, Ruellan A, Bernardeau K, Kraeber-Bodéré F, Gouard S, Loussouarn D, et al. Syndecan-1 antigen, a promising new target for triplenegative breast cancer immuno-PET and radioimmunotherapy. A preclinical study on MDA-MB-468 xenograft tumors. EJNMMI Res. 2011;1(1):20. https:// doi.org/10.1186/2191-219X-1-20.

77. Reubi JC, Maecke HR. Peptide-Based Probes for Cancer Imaging. J Nucl Med. 2008;49(11):1735-8. https://doi.org/10.2967/jnumed.108.053041.

78. Yu MK, Park J, Jon S. Targeting strategies for multifunctional nanoparticles in cancer imaging and therapy. Theranostics. 2012;2(1):3-44 http://www.thno. org/v02p0003.htm.

79. Feng G-K, Liu R-B, Zhang M-Q, Ye X-X, Zhong Q, Xia Y-F, et al. SPECT and near-infrared fluorescence imaging of breast cancer with a neuropilin-1targeting peptide. J Control Release. 2014;192:236-42 https://linkinghub. elsevier.com/retrieve/pii/S0168365914005203.

80. Crisp JL, Savariar EN, Glasgow HL, Ellies LG, Whitney MA, Tsien RY. Dual targeting of integrin av $\beta 3$ and matrix metalloproteinase-2 for optical imaging of tumors and chemotherapeutic delivery. Mol Cancer Ther. 2014; 13(6):1514-25. https://doi.org/10.1158/1535-7163.MCT-13-1067.

81. Peiris PM, Toy R, Doolittle E, Pansky J, Abramowski A, Tam M, et al. Imaging metastasis using an integrin-targeting chain-shaped nanoparticle. ACS Nano. 2012;6(10):8783-95. https://doi.org/10.1021/nn303833p.

82. Doolittle E, Peiris PM, Doron G, Goldberg A, Tucci S, Rao S, et al. Spatiotemporal Targeting of a Dual-Ligand Nanoparticle to Cancer Metastasis. ACS Nano. 2015;9(8):8012-21. https://doi.org/10.1021/acsnano.5b01552.

83. Ali MM, Varma NRS, Janic B, Zhang L. Cancer Res. 2015;75(9). https://doi.org/ 10.1158/1538-7445.BRAIN15-IA09.

84. Chung ZY, Kim MW. Biomd Res Int. 2014;2014(81932).

85. Meier R, Henning TD, Boddington S, Tavri S, Arora S, Piontek G, et al. Breast cancers: MR imaging of folate-receptor expression with the folate-specific nanoparticle P1133. Radiology. 2010;255(2):527-35. https://doi.org/10.1148/ radiol.10090050

86. Feng B, Xu Z, Zhou F, Yu H, Sun Q, Wang D, et al. Nanoscale. 2015;36: 14854-64.

87. Cao L, Yang S-T, Wang X, Luo PG, Liu J-H, Sahu S, et al. Competitive performance of carbon \&quot;quantum\&quot; dots in optical bioimaging. Theranostics. 2012;2(3):295-301 http://www.thno.org/v02p0295.htm.

88. Mishra AC, Luker KE, Durmaz H, Luker GD. Biomacromolecules. 2015;8:2412-7.

89. Zevon M, Ganapathy V, Kantamneni H, Mingozzi M, Kim P, Adler D, et al. CXCR4 Targeted, Short Wave Infrared (SWIR) Emitting Nanoprobes for Enhanced Deep Tissue Imaging and Micrometastatic Cancer Lesion Detection. Small. 2015;11(47):6347-57. https://doi.org/10.1002/smll.201502202.

90. Wang S, Zhang JWY. Biol Med. 2016;2:411-20.

91. Liu Z, Liang X-J. Nano-carbons as theranostics. Theranostics. 2012;2(3):235-7. http://www.thno.org/v02p0235.htm.

92. Chen Z, Ma L, Liu Y, Chen C. Applications of Functionalized Fullerenes in Tumor Theranostics. Theranostics. 2012;2(3):238-50 http://www.thno.org/v02p0238.htm.

93. Zeltins A. Construction and characterization of virus-like particles: a review. Mol Biotechnol. 2013;53(1):92-107. https://doi.org/10.1007/s12033-012-9598-4.

94. Grasso S, Santi L. Viral nanoparticles as macromolecular devices for new therapeutic and pharmaceutical approaches. Int J Physiol Pathophysiol Pharmacol. 2010;2(2):161-78 http://www.ncbi.nlm.nih.gov/pubmed/21383 892.

95. Guu TSY, Liu Z, Ye Q, Mata DA, Li K, Yin C, et al. Structure of the hepatitis E virus-like particle suggests mechanisms for virus assembly and receptor 
binding. Proc Natl Acad Sci U S A. 2009;106(31):12992-7. https://doi.org/10 1073/pnas.0904848106.

96. Ashley CE, Carnes EC, Phillips GK, Durfee PN, Buley MD, Lino CA, et al. Cellspecific delivery of diverse cargos by bacteriophage MS2 virus-like particles. ACS Nano. 2011;5(7):5729-45. https://doi.org/10.1021/nn201397z.

97. Cortes-Perez NG, Sapin C, Jaffrelo L, Daou S, Grill JP, Langella P, et al. Rotavirus-like particles: a novel nanocarrier for the gut. J Biomed Biotechnol. 2010;2010:317545 http://www.hindawi.com/journals/bmri/2010/317545/.

98. Zochowska M, Paca A, Schoehn G, Andrieu J-P, Chroboczek J, Dublet B, et al. Adenovirus Dodecahedron, as a Drug Delivery Vector. Jagetia GC, editor. PLoS One. 2009;4(5):e5569. https://doi.org/10.1371/journal.pone.0005569.

99. Sharma A, Goyal AK, Rath G. Recent advances in metal nanoparticles in cancer therapy. J Drug Target. 2018;26(8):617-32. https://doi.org/10.1080/ 1061186X.2017.1400553.

100. Twelves C, Jove M, Gombos A, Awada A. Cytotoxic chemotherapy: Still the mainstay of clinical practice for all subtypes metastatic breast cancer. Crit Rev Oncol Hematol. 2016;100:74-87 https://linkinghub.elsevier.com/retrieve/ pii/S104084281630021X.

101. Gradishar WJ, Anderson BO, Balassanian R, Blair SL, Burstein HJ, Cyr A, et al. NCCN Guidelines Insights Breast Cancer, Version 1.2016. J Natl Compr Canc Netw. 2015;13(12):1475-85 http:/www.ncbi.nlm.nih.gov/pubmed/26656517.

102. Denkert C, Liedtke C, Tutt A, von Minckwitz G. Molecular alterations in triple-negative breast cancer-the road to new treatment strategies. Lancet (London, England). 2017;389(10087):2430-42 https://linkinghub.elsevier.com/ retrieve/pii/S0140673616324540.

103. Yao H, He G, Yan S, Chen C, Song L, Rosol TJ, et al. Triple-negative breast cancer: is there a treatment on the horizon? Oncotarget. 2017;8(1):1913-24 http://www.oncotarget.com/fulltext/12284.

104. Audeh MW. Novel treatment strategies in triple-negative breast cancer: specific role of poly(adenosine diphosphate-ribose) polymerase inhibition. Pharmgenomics Pers Med. 2014;7:307-16 http://www.dovepress.com/novel-treatment-strategies-intriple-negative-breast-cancer-specific-r-peer-reviewed-article-PGPM.

105. Balmaña J, Tung NM, Isakoff SJ, Graña B, Ryan PD, Saura C, et al. Phase I trial of olaparib in combination with cisplatin for the treatment of patients with advanced breast, ovarian and other solid tumors. Ann Oncol Off J Eur Soc Med Oncol. 2014;25(8):1656-63. https://doi.org/10.1093/annonc/mdu187.

106. Sobande F, Dušek L, Matějková A, Rozkoš T, Laco J, Ryška A. EGFR in triple negative breast carcinoma: significance of protein expression and high gene copy number. Cesk Patol. 2015;51(2):80-6 http://www.ncbi.nlm.nih. gov/pubmed/25970719.

107. Tsimafeyeu I, Ludes-Meyers J, Stepanova E, Daeyaert F, Khochenkov D, Joose J-B, et al. Targeting FGFR2 with alofanib (RPT835) shows potent activity in tumour models. Eur J Cancer. 2016;61:20-8 https://inkinghub. elsevier.com/retrieve/pii/S0959804916320305.

108. Hu X, Zhang J, Xu B, Jiang Z, Ragaz J, Tong Z, et al. Multicenter phase II study of apatinib, a novel VEGFR inhibitor in heavily pretreated patients with metastatic triple-negative breast cancer. Int J Cancer. 2014;135(8):19619. https://doi.org/10.1002/ijc.28829.

109. Kim YJ, Choi J-S, Seo J, Song J-Y, Eun Lee S, Kwon MJ, et al. MET is a potential target for use in combination therapy with EGFR inhibition in triple-negative/basal-like breast cancer. Int J Cancer. 2014;134(10):2424-36. https://doi.org/10.1002/ijc.28566.

110. Leung EY, Amiri MA, Finlay GJ, Rewcastle GW, Baguley BC. PlosOne. 2015;10:1-18,

111. Kim S, Lee J, Jeon M, Lee JE, Nam SJ. MEK-dependent IL-8 induction regulates the invasiveness of triple-negative breast cancer cells. Tumour Biol. 2016;37(4): 4991-9. Available from:. https://doi.org/10.1007/s13277-015-4345-7.

112. Kim EMH, Mueller K, Gartner E, Boerner J. Dasatinib is synergistic with cetuximab and cisplatin in triple-negative breast cancer cells. J Surg Res. 2013;185(1):231-9 https://linkinghub.elsevier.com/retrieve/pii/S00224 80413006677

113. Brazelle W, Kreahling JM, Gemmer J, Ma Y, Cress WD, Haura E, et al. Histone deacetylase inhibitors downregulate checkpoint kinase 1 expression to induce cell death in non-small cell lung cancer cells. Morty RE, editor. PLoS One. 2010;5(12):e14335. https://doi.org/10.1371/ journal.pone.0014335

114. Proia DA, Zhang C, Sequeira M, Jimenez J-P, He S, Spector N, et al. Preclinical activity profile and therapeutic efficacy of the HSP90 inhibitor ganetespib in triple-negative breast cancer. Clin Cancer Res. 2014;20(2):413-24. https://doi. org/10.1158/1078-0432.CCR-13-2166.

115. Caiazza F, Murray A, Madden SF, Synnott NC, Ryan EJ, O'Donovan N, et al. Endocr Relat Cancer. 2016;40:433-42.
116. Roger S, Gillet L, Le Guennec J-Y, Besson P. Voltage-gated sodium channels and cancer: is excitability their primary role? Front Pharmacol. 2015;29:6. https://doi.org/10.3389/fphar.2015.00152/abstract.

117. Conner JB, Bawa R, Nicholas M, Weinstein V. Handbook of Clinical Nanomedicine - From Bench to Bedside. Singapore: Pan Stanford Publishing Pte Ltd; 2014. p.1-31.

118. Tran S, DeGiovanni P-J, Piel B, Rai P. Cancer nanomedicine: a review of recent success in drug delivery. Clin Transl Med. 2017;6(1):44. https://doi. org/10.1186/s40169-017-0175-0.

119. Miele E, Spinelli GP, Miele E, Tomao F, Tomao S. Albumin-bound formulation of paclitaxel (Abraxane ABI-007) in the treatment of breast cancer. Int J Nanomedicine. 2009;4:99-105 http://www.ncbi.nlm.nih.gov/pubmed/19516888.

120. ClinicalTrials.gov (2000) National Library of Medicine (US), Bethesda. Identifier NCT02596373. A study of mitoxantrone hydrochloride liposome injection in advanced recurrent or metastatic breast cancer; 2015 Nov 2 [about 5 screens]. https:/www.clinicaltrials.gov/ct2/show/NCT02596373?term=Mitoxantrone+ $\mathrm{HCL}+$ Liposome+Injection\&rank=4. Accessed 6 July 2017.

121. LiPlaCis. 2017. Oncology venture. http://www.oncologyventure.com/ pipeline/liplacis/

122. Jia H, Truica Cl, Wang B, Wang Y, Ren $X$, Harvey HA, et al. Immunotherapy for triple-negative breast cancer: Existing challenges and exciting prospects. Drug Resist Updat. 2017;32:1-15 https://linkinghub.elsevier.com/retrieve/pii/ S1368764617300316.

123. Vansteenkiste J, De Ruysscher D, Eberhardt WEE, Lim E, Senan S, Felip E, et al. Early and locally advanced non-small-cell lung cancer (NSCLC): ESMO Clinical Practice Guidelines for diagnosis, treatment and follow-up. Ann Oncol Off J Eur Soc Med Oncol. 2013;24 Suppl 6(suppl 6):vi89-98. https:// doi.org/10.1093/annonc/mdt241.

124. Walter S, Weinschenk T, Stenzl A, Zdrojowy R, Pluzanska A, Szczylik C, et al. Nat Med. 2012;18:1254-61.

125. Joura EA, Giuliano AR, Iversen OE, Bouchard C, Mao C, Mehlsen J, et al. Engl J Med. 2015:372:711-23.

126. Tiriveedhi V, Tucker N, Herndon J, Li L, Sturmoski M, Ellis M, et al. Clin Cancer Res. 2014;20:5964-75.

127. Pan K, Guan X-X, Li Y-Q, Zhao J-J, Li J-J, Qiu H-J, et al. Clinical activity of adjuvant cytokine-induced killer cell immunotherapy in patients with postmastectomy triple-negative breast cancer. Clin Cancer Res. 2014;20(11): 3003-11. https://doi.org/10.1158/1078-0432.CCR-14-0082.

128. Laumbacher B, Gu S, Wank R. Activated monocytes prime naïve T cells against autologous cancer: vigorous cancer destruction in vitro and in vivo. Scand J Immunol. 2012;75(3):314-28. https://doi.org/10.1111/j.1365-3083. 2011.02652.x.

129. Diaconu I, Ballard B, Zhang M, Chen Y, West J, Dotti G, et al. Inducible Caspase-9 Selectively Modulates the Toxicities of CD19-Specific Chimeric Antigen Receptor-Modified T Cells. Mol Ther. 2017;25(3):580-92 https:// linkinghub.elsevier.com/retrieve/pii/S1525001617300175.

130. Rijavec E, Genova C, Alama A, Barletta G, Sini C, Pronzato P, et al. Role of immunotherapy in the treatment of advanced non-small-cell lung cancer. Future Oncol. 2014;10(1):79-90. https://doi.org/10.2217/fon.13.145.

131. Kapadia CH, Perry JL, Tian S, Luft JC, DeSimone JM. Nanoparticulate immunotherapy for cancer. J Control Release. 2015;219:167-80 https:// linkinghub.elsevier.com/retrieve/pii/S0168365915301620.

132. Vesely MD, Kershaw MH, Schreiber RD, Smyth MJ. Natural innate and adaptive immunity to cancer. Annu Rev Immunol. 2011;29(1):235-71. https://doi.org/10.1146/annurev-immunol-031210-101324.

133. Topalian SL, Drake CG, Pardoll DM. Immune checkpoint blockade: a common denominator approach to cancer therapy. Cancer Cell. 2015; 27(4):450-61 https://linkinghub.elsevier.com/retrieve/pii/S1535610815 000896.

134. Garon EB, Rizvi NA, Hui R, Leighl N, Balmanoukian AS, Eder JP, et al. Pembrolizumab for the treatment of non-small-cell lung cancer. N Engl J Med. 2015;372(21):2018-28. https://doi.org/10.1056/NEJMoa1501824.

135. Tung N, Garber JE, Hacker MR, Torous V, Freeman GJ, Poles E, et al. Prevalence and predictors of androgen receptor and programmed deathligand 1 in BRCA1-associated and sporadic triple-negative breast cancer. NPJ Breast Cancer. 2016;2(1):16002 http://www.nature.com/articles/ npjbcancer20162.

136. Nanda R, Chow LQM, Dees EC, Berger R, Gupta S, Geva R, et al. Pembrolizumab in Patients With Advanced Triple-Negative Breast Cancer: Phase Ib KEYNOTE-012 Study. J Clin Oncol. 2016:34(21):2460-7. https://doi. org/10.1200/JCO.2015.64.8931. 
137. Liu Y, Wang X, Hussain M, Lv M, Dong X, Wang T, et al. Theranostics Applications of Nanoparticles in Cancer Immunotherapy. Med Sci. 2018;6(4): 100 http://www.ncbi.nlm.nih.gov/pubmed/30424010.

138. Adams S, Diamond JR, Hamilton EP, Pohlmann PP, Tolaney SM, Molinero L, et al. Abstract presented at: 2016 ASCO Annual Meeting. J Clin Oncol. 2016:34:abstract 1009.

139. Shih K, Arkenau HT, Infante JR. Drugs. 2014;74:1993-2013.

140. Tuophy K, Jaini R, Johnson JM, Loya MG, Wilk D, Owns E. Cancers8; 2016.

141. Zhang P, Yi S, Li X, Liu R, Jiang H, Huang Z, et al. Preparation of triple-negative breast cancer vaccine through electrofusion with day-3 dendritic cells. PLoS One. 2014;9(7):e102197. https://doi.org/10.1371/journal.pone.0102197.

142. Dua I, Antoinette R. AJHO. 2017;13:20-7.

143. Su X, Wang Z, Li L, Zheng M, Zheng C, Gong P, et al. Lipid-polymer nanoparticles encapsulating doxorubicin and 2'-deoxy-5-azacytidine enhance the sensitivity of cancer cells to chemical therapeutics. Mol Pharm. 2013;10(5):1901-9. https://doi.org/10.1021/mp300675c.

144. Tran TH, Ramasamy T, Truong DH, Shin BS, Choi H-G, Yong CS, et al. Development of vorinostat-loaded solid lipid nanoparticles to enhance pharmacokinetics and efficacy against multidrug-resistant cancer cells. Pharm Res. 2014;31(8):1978-88. https://doi.org/10.1007/s11095-014-1300-z.

145. Christian DA, Hunter CA. Particle-mediated delivery of cytokines for immunotherapy. Immunotherapy. 2012;4(4):425-41. https://doi.org/10.2217/imt.12.26.

146. Xu Z, Wang Y, Zhang L, Huang L. Nanoparticle-delivered transforming growth factor- $\beta$ siRNA enhances vaccination against advanced melanoma by modifying tumor microenvironment. ACS Nano. 2014;8(4):3636-45. https://doi.org/10.1021/nn500216y.

147. Cheng N, Watkins-Schulz R, Junkins RD, David CN, Johnson BM, Montgomery SA, et al. A nanoparticle-incorporated STING activator enhances antitumor immunity in PD-L1-insensitive models of triple-negative breast cancer. JCl Insight. 2018;15, 3(22) https://insight.jci.org/articles/view/120638.

148. Ye Y, Wang J, Hu Q, Hochu GM, Xin H, Wang C, et al. Synergistic Transcutaneous Immunotherapy Enhances Antitumor Immune Responses through Delivery of Checkpoint Inhibitors. ACS Nano. 2016;10(9):8956-63. https://doi.org/10.1021/acsnano.6b04989.

149. Oberli MA, Reichmuth AM, Dorkin JR, Mitchell MJ, Fenton OS, Jaklenec A, et al. Lipid Nanoparticle Assisted mRNA Delivery for Potent Cancer Immunotherapy. Nano Lett. 2017;17(3):1326-35. https://doi.org/10.1021/acs. nanolett.6b03329.

150. Yazdi MH, Mahdavi M, Faghfuri E, Faramarzi MA, Sepehrizadeh Z, Hassan ZM, et al. Th1 Immune Response Induction by Biogenic Selenium Nanoparticles in Mice with Breast Cancer: Preliminary Vaccine Model. Iran J Biotechnol. 2015;13(2):1-9 http://ijbiotech.com/article_10883_1637.html.

151. Varypataki EM, van der Maaden K, Bouwstra J, Ossendorp F, Jiskoot W. Cationic liposomes loaded with a synthetic long peptide and poly(l:C): a defined adjuvanted vaccine for induction of antigen-specific T cell cytotoxicity. AAPS J. 2015;17(1):216-26. https:/doi.org/10.1208/s12248-014-9686-4.

152. Hodge JW, Chakraborty M, Kudo-Saito C, Garnett CT, Schlom J. Multiple costimulatory modalities enhance CTL avidity. J Immunol. 2005;174(10): 5994-6004. https://doi.org/10.4049/jimmunol.174.10.5994.

153. Zhang L, Yang X, Li Y, Zheng W, Jiang X. Carbon. 2017;121:79-89.

154. Min Y, Roche KC, Tian S, Eblan MJ, McKinnon KP, Caster JM, et al. Antigencapturing nanoparticles improve the abscopal effect and cancer immunotherapy. Nat Nanotechnol. 2017;12(9):877-82 http://www.nature. com/articles/nnano.2017.113.

155. Pham E, Yin M, Peters CG, Lee CR, Brown D, Xu P, et al. Preclinical Efficacy of Bevacizumab with CRLX101, an Investigational Nanoparticle-Drug Conjugate, in Treatment of Metastatic Triple-Negative Breast Cancer. Cancer Res. 2016;76(15):4493-503. https://doi.org/10.1158/0008-5472.CAN-15-3435.

156. Luo $M$, Wang $H$, Wang Z, Cai H, Lu Z, Li Y, et al. A STING-activating nanovaccine for cancer immunotherapy. Nat Nanotechnol. 2017;12(7):64854 http://www.nature.com/articles/nnano.2017.52.

157. Chu D, Zhao Q, Yu J, Zhang F, Zhang H, Wang Z. Nanoparticle Targeting of Neutrophils for Improved Cancer Immunotherapy. Adv Healthc Mater. 2016 5(9):1088-93. https://doi.org/10.1002/adhm.201500998.

158. Yang F, Wang F, Liu Y, Wang S, Li X, Huang Y, et al. Sulforaphane induces autophagy by inhibition of HDAC6-mediated PTEN activation in triple negative breast cancer cells. Life Sci. 2018;213:149-57 http://www.ncbi.nlm. nih.gov/pubmed/30352240.

159. Chauhan VP, Jain RK. Strategies for advancing cancer nanomedicine. Nat Mater. 2013:12(11):958-62 http://www.nature.com/articles/nmat3792.
160. Carboni E, Tschudi K, Nam J, Lu X, Ma AWK. Particle margination and its implications on intravenous anticancer drug delivery. AAPS PharmSciTech. 2014;15(3):762-71. https://doi.org/10.1208/s12249-014-0099-6.

161. Von Roemeling C, Jiang W, Chan CK, Weissman IL, Kim BYS. Breaking Down the Barriers to Precision Cancer Nanomedicine. Trends Biotechnol. 2017;35(2):159-71 https://linkinghub.elsevier.com/retrieve/pii/ S0167779916301123.

162. Bregoli L, Movia D, Gavigan-Imedio JD, Lysaght J, Reynolds J, Prina-Mello A. Nanomedicine applied to translational oncology: A future perspective on cancer treatment. Nanomedicine. 2016;12(1):81-103 https://linkinghub. elsevier.com/retrieve/pii/S1549963415001720.

163. Setyawati MI, Tay CY, Bay BH, Leong DT. Gold Nanoparticles Induced Endothelial Leakiness Depends on Particle Size and Endothelial Cell Origin. ACS Nano. 2017;11(5):5020-30. https://doi.org/10.1021/acsnano.7b01744.

164. Wang J, Zhang L, Peng F, Shi X, Leong DT. Targeting Endothelial Cell Junctions with Negatively Charged Gold Nanoparticles. Chem Mater. 2018; 30(11):3759-67. https://doi.org/10.1021/acs.chemmater.8b00840.

165. Tay CY, Setyawati MI, Leong DT. Nanoparticle Density: A Critical Biophysical Regulator of Endothelial Permeability. ACS Nano. 2017;11(3):2764-72. https://doi.org/10.1021/acsnano.6b07806.

166. Setyawati MI, Tay CY, Chia SL, Goh SL, Fang W, Neo MJ, et al. Titanium dioxide nanomaterials cause endothelial cell leakiness by disrupting the homophilic interaction of VE-cadherin. Nat Commun. 2013;4(1):1673 http:// www.nature.com/articles/ncomms2655.

167. Setyawati MI, Mochalin VN, Leong DT. Tuning Endothelial Permeability with Functionalized Nanodiamonds. ACS Nano. 2016;10(1):1170-81. https://doi. org/10.1021/acsnano.5b06487.

168. Sina AAl, Carrascosa LG, Liang Z, Grewal YS, Wardiana A, Shiddiky MJA, et al. Epigenetically reprogrammed methylation landscape drives the DNA selfassembly and serves as a universal cancer biomarker. Nat Commun. 2018; 9(1):4915 http://www.nature.com/articles/s41467-018-07214-w.

169. https://www.imveurope.com/news/one-hundred-million-frames-secondcamera-further-cancer-research

170. https://6abc.com/health/israeli-scientists-say-cancer-cure-close;-doctors-areskeptical/5112260/

171. Piqué DG, Montagna C, Greally JM, Mar JC. A novel approach to modeling transcriptional heterogeneity identifies the oncogene candidate CBX2 in invasive breast carcinoma. bioRxiv. 2018;20:303396. https://doi.org/10.1101/ 303396v1.article-info.

172. https://deepmind.com/applied/deepmind-health/working-partners/healthresearch-tomorrow/cancer-research-imperial-optimam-jikei/

173. Lu H, Arshad M, Thornton A, Avesani G, Cunnea P, Curry E, et al. A mathematicaldescriptor of tumor-mesoscopic-structure from computed-tomography images annotates prognostic- and molecular-phenotypes of epithelial ovarian cancer. Nat Commun. 2019;10(1):764 http://www.nature.com/articles/s41467-019-08718-9.

\section{Publisher's Note}

Springer Nature remains neutral with regard to jurisdictional claims in published maps and institutional affiliations.

Ready to submit your research? Choose BMC and benefit from:

- fast, convenient online submission

- thorough peer review by experienced researchers in your field

- rapid publication on acceptance

- support for research data, including large and complex data types

- gold Open Access which fosters wider collaboration and increased citations

- maximum visibility for your research: over $100 \mathrm{M}$ website views per year

At BMC, research is always in progress.

Learn more biomedcentral.com/submission 